\title{
Optimal Taxation, Redistribution, and Environmental Externalities"
}

\author{
Thomas Aronsson ${ }^{\mathrm{a}}$ and Tomas Sjögren ${ }^{\mathrm{s}}$
}

June 2017

\begin{abstract}
This paper surveys research on optimal redistributive taxation in economies with environmental externalities. A major question is whether externality correction only motivates an adjustment of the tax policy rule for the externality-generating activity, or whether the marginal value of the externality directly enters the policy rules for other tax instruments as well. In a static benchmark model with an atmospheric consumption externality, where the government uses a mix of a nonlinear income tax and linear commodity taxes, we show that Sandmo's (1975) additivity property applies. This means that externality correction leads to an additional term (measuring the marginal value of the externality) in the commodity tax formula for the externality generating good, while the policy rules for commodity taxation of clean goods and marginal income taxation take the same form as in the absence of any externality. We also extend this benchmark model to capture a number of scenarios (such as non-atmospheric externalities, border trade in the externality generating good, and competition between governments in a multi-country framework), where the additivity property no longer applies. We end by examining an intertemporal model of optimal taxation with a stock-externality, allowing us to integrate the study of optimal redistributive taxation with literature on environmental economics and policy based on dynamic models.
\end{abstract}

JEL: D60, D62, H21, H23, Q51.

Keywords: Environmental externalities, optimal taxation, redistribution, income taxation, commodity taxation.

\footnotetext{
* The authors would like to thank David Granlund for helpful comments and suggestions. Research grants from the Swedish Research Council (ref 2016-02371) are also gratefully acknowledged.

a Address: Department of Economics, Umeå School of Business and Economics, Umeå University, SE - 901 87, Umeå Sweden. E-mail: Thomas.Aronsson@econ.umu.se.

${ }^{s}$ Address: Department of Economics, Umeå School of Business and Economics, Umeå University, SE - 90187 , Umeå Sweden. E-mail: Tomas.Sjogren@econ.umu.se.
} 


\section{Introduction}

This paper gives a selective overview of research on optimal taxation in economies with environmental externalities. The purpose is to summarize and discuss what we believe are the central messages of this research. In doing so, we shall simultaneously address corrective and redistributive aspects of the underlying theory as well as some of the important implications thereof. We will also discuss some of the more recent research directions in this area.

The study of corrective taxation in economies with externalities, i.e., how to use tax policy to achieve the desired allocation of resources from society's point of view, has a long history in economics. The Pigouvian tax refers back to Pigou (1920), who wanted to rectify discrepancies between what he called the marginal private net product and the marginal social net product, and he described these discrepancies in a way interpretable as externalities. ${ }^{1}$ One of his examples referred to smoke from factory chimneys, which was a major environmental problem at that time and imposed large welfare costs on the neighboring community. The smoke case exemplifies a situation where the marginal social net product falls short of the marginal private net product, and Pigou argued that a tax could eliminate this discrepancy and thus - if using modern language fully internalize the negative externality. ${ }^{2}$ He presented the analogous argument for a subsidy (referred to as "bounty") when the marginal social net product exceeds the marginal private net product.

Modern literature on taxation in economies with externalities recognizes that the tax system typically plays multiple roles. Besides correcting for externalities and other market failures, the tax system must be designed to achieve the desired distribution among individuals and must also raise sufficient revenue to fund publically provided goods. A seminal contribution here is Sandmo (1975), who examined the problem of optimal linear commodity taxation when the

\footnotetext{
${ }^{1}$ See Pigou (1920), Part II, Chapter 11.

${ }^{2}$ Somewhat ironically, Pigou does not seem to have been the first economist to suggest a "Pigouvian tax" to achieve the socially efficient allocation of resources. In 1911, the Danish economist Jens Warming proposed a tax policy to internalize the market failure of open-access fisheries; see Warming (1911), where he also derived the exact policy rule for this tax. Warming wrote in Danish, and his work was translated into English first in 1983 (see Andersen, 1983).
} 
aggregate consumption of one of the commodities generates a negative externality. In his model, the externality is atmospheric in the sense that each consumer's marginal contribution to this externality is the same. This leads to the famous additivity property, which means that externality correction results in an additional, additive term in the policy rule for the commodity tax on the externality-generating commodity (which reflects the marginal social value of the externality that each individual imposes on other persons), whereas the policy rules for the other commodity taxes take the same form as in the absence of any market failure. The practical policy message is the principle of targeting: when the tax on the externality-generating commodity is a perfect instrument for correction (which it is when the externality is atmospheric), it suffices to tax the externality-generating commodity; there is no reason to tax complements to, or subsidize substitutes for, this commodity for purposes of externality correction (even if these commodities might be taxed or subsidized for other reasons). As will be explained below, this does not mean that the levels of the other tax instrument do not change in response to externalities; only that the policy incentives (as reflected in the policy rules for these instruments) remain unaffected.

However, if the externality is non-atmospheric, such that individuals impose externalities on each other at different degrees, or if there is a discrepancy between the externality-generating activity and the base of the corrective tax, the principle of targeting is not in general valid (see, e.g., Diamond, 1973, and Sandmo, 1976). With a non-atmospheric externality, an exception arises if the externality can be taxed based on individual-specific rates; however, this is typically not feasible. In this case, it may be desirable to supplement the tax on the externality-generating good with corrective taxes or subsidies on other goods, despite that the consumption of these goods does not cause any externalities. Eckerstorfer and Wendner (2013) derived a similar result in a model where relative consumption concerns lead to a non-atmospheric consumption externality. They showed that the government would need individual-specific commodity taxes to implement a first-best resource allocation.

Environmental externalities were integrated into the theory of optimal nonlinear taxation by Pirttilä and Tuomala (1997). ${ }^{3}$ In their study, the government (or social planner) solves a mixed

\footnotetext{
${ }^{3}$ Their model is an extension of the discrete mixed tax problem with two consumer types developed by Edwards, Keen, and Tuomala (1994).
} 
tax problem where the set of policy instruments contains a nonlinear income tax and linear commodity taxes. Such a framework provides a reasonably realistic description of the set of tax instruments that many governments have at their disposal. Furthermore, the use of distortionary taxes is, in this case, an optimal choice subject to informational constraints; it is not a consequence of arbitrary restrictions on the tax instruments. Pirttilä and Tuomala followed Sandmo (1975) in assuming that the externality is atmospheric (and given by the aggregate consumption of a "dirty" good), and found that the additivity property carries over to a general model of optimal mixed taxation. This result further emphasizes the importance of targeting as one of the main messages of the literature on optimal taxation under externalities. A similar research problem, yet with the modification that the environmental consumption externalities are generated in production (instead of in consumption), and where the government has access to an emission tax alongside the income and commodity taxes, was examined by Cremer and Gahvari (2001). In their model, a flexible emission tax (levied on the firms that produce the externalitygenerating goods) constitutes a perfect instrument for correction. The mixed tax problem with environmental externalities was later extended to various multi-country settings with transboundary externalities by Aronsson and Blomquist (2003) and Aronsson, Persson, and Sjögren (2010), in which non-cooperative and cooperative resource allocations are compared from the perspective of tax policy.

Based on the aforementioned studies, the models examined below assume that the set of tax instruments used for redistribution and externality correction includes a nonlinear income tax and linear commodity taxes. We shall also, in most cases, assume that information asymmetries prevent the government from lump-sum redistribution, meaning that the best achievable resource allocation is a second-best allocation. Although we focus on environmental externalities and their implications for tax policy, our study is thus closely connected to, and draws upon, a broad literature on optimal redistribution under consumption externalities, which includes environmental problems (e.g., Pirttilä and Tuomala, 1997; Cremer, Gahvari, and Ladoux, 1998; Cremer and Gahvari, 2001; Aronsson and Blomquist, 2003; Aronsson, Persson, and Sjögren, 2010), positional externalities (e.g., Oswald, 1983; Tuomala, 1990; Aronsson and JohanssonStenman, 2008, 2010, 2015; Aronsson and Mannberg, 2014), and altruism (e.g., Oswald, 1983). In addition, since our main concern is to characterize an optimal tax policy, we refrain from 
analyzing environmental tax reforms in what follows (as the need for such reforms presupposes that the initial tax structure is suboptimal from society's point of view). ${ }^{4}$

In Section 2, we present a static benchmark model with heterogeneous individuals, where the consumption of a particular commodity - to be referred to as a "dirty good" - causes an atmospheric environmental externality. Following much of the earlier literature referred to above, we consider a model where the consumers are of two types depending on their inherent earningsability. This gives a convenient, albeit analytically powerful, model in which to address the redistributive and corrective aspects of taxation simultaneously. Unless stated otherwise, we assume that the government has access to a general, nonlinear income tax and linear commodity taxes. The reason for using the term "benchmark model" is that it constitutes our analytical starting point, providing a unified framework which can be modified and further developed in later sections to address the different issues at hand. The analyses carried out below are thus based on models sharing these basic characteristics, which is convenient for purposes of comparison. We end Section 2 by briefly discussing a first-best resource allocation (based on the assumption that individual productivity is observable) and present the Pigouvian tax that fully internalizes the environmental externality.

In Section 3, we examine the benchmark model in a setting where the earnings-ability (as reflected in the individuals' before-tax wage rates) is private information, which rules out redistribution through type-specific lump sum taxes. The optimal tax structure in this model satisfies the additivity property: the social value of the marginal externality enters additively in the formula for the tax on the externality-generating good, while it neither enters the policy rules for other commodity taxes nor the policy rule for marginal income taxation. We also show how and why the externality-correcting part of the commodity tax on the dirty good deviates from the first-best Pigouvian tax.

In Section 4, we consider two possible extensions of the benchmark model, where the additivity property no longer applies. Subsection 4.1 examines a case with a non-atmospheric externality

\footnotetext{
${ }^{4}$ Environmental tax reform was the topic of a series of articles by Lans Bovenberg and co-authors starting in the 1990s; see, e.g., Bovenberg and de Mooij (1994) and Bovenberg and Goulder (1997).
} 
such that the individuals differ in their marginal contribution to this externality. We show (i) that the corrective part of the dirty good tax typically reflects a weighted average of the marginal externality that each individual-type generates, and (ii) that the taxes on clean goods as well as the income tax will serve as supplemental instruments for correction. A scenario with border trade, where the externality-generating good can either be bought at home or abroad, is addressed in subsection 4.2. With flexible instruments for trade policy, this model replicates the optimal tax structure derived in Section 3. However, if trade agreements prevent such trade policy, the optimal tax structure (from the domestic government's perspective) resembles that derived in subsection 4.1, where taxes on clean goods as well as the income tax are also used for externality correction.

In Section 5, we consider a two-country model with a transboundary environmental externality. When the externality that each country generates spills over on other countries, a socially efficient tax policy would typically require international policy cooperation, and we briefly discuss the optimal tax policy implicit in a cooperative equilibrium. We also analyze the tax policy implicit in a non-cooperative Nash equilibrium, as well as the scope for marginal policy coordination in the Nash equilibrium.

Section 6 extends the analysis to an overlapping generations (OLG) model with stock-pollution. This setting allows us to connect the literature on second-best taxation of environmental externalities, where the bulk of earlier studies are based on static models, to the literature on environmental externalities and policy in dynamic models. ${ }^{5}$ Section 7 concludes.

\section{A Benchmark Model}

In this section, we develop a benchmark model to be further used and elaborated on in later sections. The individuals/consumers of this economy differ in their innate earnings-ability, and we follow much earlier literature in distinguishing between two such individual types; a low-

\footnotetext{
${ }^{5}$ See, e.g., Keeler, Spence, and Zeckhauser (1971), Brock (1977), and Tahvonen and Kuuluvainen (1994). See also Aronsson, Johansson, and Löfgren (1997) and the references therein.
} 
ability type $(j=1)$ and high-ability type $(j=2) .{ }^{6}$ Without any loss of generality, we normalize the number of individuals of each such type on one, while still retaining the assumption that each individual is an atomistic agent and treats economy-wide variables as exogenous.

\section{Private Sector}

Each individual consumer has preferences over a numeraire clean good, $c^{j}$, a non-numeraire clean good, $y^{j}$, an environmentally dirty good, $x^{j}$, leisure, $z^{j}$, and environmental damage, $E$. $^{7}$ To begin with, we assume that the environmental damage is given by the aggregate consumption of the dirty good such that $E=x^{1}+x^{2}$, which means that the environmental externality is atmospheric. As we mentioned above, the individuals differ in their innate earnings-ability, which is here interpreted to mean that the low-ability type (type 1) faces a lower before-tax hourly wage than the high-ability type (type 2). All individuals share a common utility function, and the utility facing any individual of ability-type $j(j=1,2)$ is written as follows:

$$
u^{j}=u\left(c^{j}, x^{j}, y^{j}, z^{j}, E\right)
$$

where leisure, $z^{j}=1-l^{j}$, is defined as a time endowment normalized to one less the hours of work, $l^{j}$. The utility function is assumed to be increasing in consumption and leisure (i.e., $c, x, y$, and $z$ ), decreasing in $E$, and strictly quasi-concave. The individual's budget constraint is given by

$$
w^{j} l^{j}-T\left(w^{j} l^{j}\right)=c^{j}+q_{x} x^{j}+q_{y} y^{j} .
$$

In equation (2), $T\left(w^{j} l^{j}\right)$ denotes an income tax payment (positive or negative). Following earlier comparable literature, we interpret $T(\cdot)$ as a general income tax, which is flexible enough to allow the government to implement any desirable combination of work hours and disposable income for each ability-type subject to relevant constraints. ${ }^{8}$ In the special case where the individual's earnings-ability is observable, $T\left(w^{j} l^{j}\right)$ reduces to an ability-type-specific lump-sum

\footnotetext{
${ }^{6}$ The two-type version of the Mirrleesian optimal income tax model originates from Stern (1982) and Stiglitz (1982), and was later extended to a model of optimal mixed taxation by Edwards, Keen, and Tuomala (1994).

7 Since environmental damage can be thought of as the negative of environmental quality, an alternative interpretation is, of course, that the consumer has preferences over environmental quality.

${ }^{8}$ At the individual's optimum point, we can rewrite the left-hand side of equation (2) in terms of a local, incomespecific marginal wage rate and a virtual income component.
} 
tax. The consumer prices are given by $q_{x}=p_{x}+t_{x}$ and $q_{y}=p_{y}+t_{y}$, where $p_{x}$ and $p_{y}$ are produces prices, and $t_{x}$ and $t_{y}$ are commodity taxes. Commodity $c$ (the numeraire) is untaxed.

An individual of ability-type $j$ chooses $l^{j}, c^{j}, x^{j}$ and $y^{j}$ to maximize the utility function given in equation (1) subject to the budget constraint in equation (2). In doing so, each individual is assumed to treat the before-tax wage rate, the consumer prices, the environmental damage, and the parameters of the tax function as exogenous.

For purposes of analytical convenience, we follow Christiansen (1984) and solve the individual's optimization problem in two stages. This approach gives commodity demand and indirect utility functions defined conditional on the hours of work, which will be used in the optimal tax problem set out below. In the first stage, we choose $c^{j}, x^{j}$ and $y^{j}$ to maximize the utility subject to the budget constraint $b^{j}=c^{j}+q_{x} x^{j}+q_{y} y^{j}$, where $b^{j}$ is a fixed post-tax income. The solution to this maximization problem gives the following conditional demand functions:

$$
\begin{aligned}
& c^{j}=c\left(b^{j}, q_{x}, q_{y}, z^{j}, E\right) \\
& x^{j}=x\left(b^{j}, q_{x}, q_{y}, z^{j}, E\right) \\
& y^{j}=y\left(b^{j}, q_{x}, q_{y}, z^{j}, E\right) .
\end{aligned}
$$

Substituting the conditional demand functions into the direct utility function gives the conditional indirect utility function

$$
v^{j}=v\left(b^{j}, q_{x}, q_{y}, z^{j}, E\right)
$$

In the second stage, we can derive the hours of work by maximizing the conditional indirect utility function with respect to $l^{j}$ and $b^{j}$ subject to $z^{j}=1-l^{j}$ and $b^{j}=w^{j} l^{j}-T\left(w^{j} l^{j}\right)$. By letting $I^{j}=w^{j} l^{j}$ denote the labor income of an individual of type $j$, the first-order condition for work hours can be written as follows:

$$
v_{b}^{j} w^{j}\left(1-T_{I}^{j}\right)=v_{z}^{j}
$$


where $T_{I}^{j}=d T\left(I^{j}\right) / d I^{j}$ is the marginal income tax rate. Subscripts attached to the utility function denote partial derivatives, i.e., $v_{b}^{j}=\partial v^{j} / \partial b^{j}$ and $v_{z}^{j}=\partial v^{j} / \partial z^{j}$.

Turning to production, we assume that the output (of all three goods) is produced by a linear technology such that the producer prices and wage rate are fixed. This assumption will be relaxed in Section 5, where we consider a model with endogenous producer prices.

\section{First-Best Pigouvian Taxation in the Benchmark Model}

In studying tax policy incentives, we will focus on the general objective of reaching a Pareto efficient resource allocation. The policy rules for marginal income and commodity taxation presented below are, therefore, consistent with the maximization of any social welfare function satisfying the Pareto criterion. More specifically, we assume that the government (or social planner) maximizes the utility of the low-ability type subject to a given level of utility, $\bar{v}^{2}$, for the high-ability type. To begin with, we also assume that the government can observe the earningsability of each individual; however, this assumption will be relaxed in Section 3 below.

The government's budget constraint is given by $\sum_{j}\left(T\left(I^{j}\right)+t_{x} x^{j}+t_{y} y^{j}\right)=0$, which we will write as follows by using $T\left(I^{j}\right)=w^{j} l^{j}-b^{j}$ for $j=1,2$ :

$$
\sum_{j}\left(w^{j} l^{j}-b^{j}+t_{x} x^{j}+t_{y} y^{j}\right)=0
$$

Since $T(\cdot)$ is a general income tax, the government can implement any desired combination of work hours and disposable income for each ability-type. Therefore, instead of parameterizing the function $T\left({ }^{\cdot}\right)$, it is common in the literature to use $l^{1}, b^{1}, l^{2}$, and $b^{2}$ as direct decision-variables in the social optimization problem. The marginal income tax rates are then calculated by comparing the social and private first-order conditions. The social decision-problem is to choose $l^{1}, b^{1}, l^{2}$, $b^{2}, t_{x}$ and $t_{y}$ to maximize the utility of the low-ability type subject to the minimum utility restriction for the high-ability type mentioned above, the public budget constraint given in equation (6), and the equation for the environmental damage, $E=\sum_{j} x^{j}$. As such, the government recognizes how the externality is determined and incorporates this information into its decision-problem. The Lagrangean can then be written as follows: 


$$
L=v^{1}+\eta\left(v^{2}-\bar{v}^{2}\right)+\mu\left(E-\sum_{j} x^{j}\right)+\gamma \sum_{j}\left(w^{j} l^{j}-b^{j}+t_{x} x^{j}+t_{y} y^{j}\right)
$$

where $\eta, \mu$ and $\gamma$ are Lagrange multipliers associated with the minimum utility restriction, the environmental constraint and the government's budget constraint, respectively. By writing the environmental constraint as an explicit Lagrange restriction, $E$ will be treated as an additional (and artificial) decision-variable (to be chosen simultaneously with $b^{1}, l^{1}, b^{2}, l^{2}, t_{x}$, and $t_{y}$ ).

The social first-order conditions derived from equation (7) are special cases of equations (11a)(11g) below and will not be presented here. Let $M W P_{E, b}^{j}=-v_{E}^{j} / v_{b}^{j}>0$ denote the marginal willingness to pay for a cleaner environment by any individual of ability-type $j$. The solution to the social decision-problem set out above then implies that the following conditions are satisfied: ${ }^{9}$

$$
v_{b}^{1}=\eta v_{b}^{2}, \quad T_{I}^{1}=T_{I}^{2}=0, \quad t_{x}=\sum_{j} M W P_{E, b}^{j}, \quad t_{y}=0 .
$$

The conditions in (8) reflect that the government can redistribute through ability-type-specific lump-sum taxes in the absence of any information asymmetries. First, complete income redistribution is attainable in the sense that the social marginal utility of consumption is equalized among ability-types, i.e., $v_{b}^{1}=\eta v_{b}^{2}$. To see this interpretation, note that the Lagrange multiplier $\eta$ (attached to the minimum utility restriction of the high-ability type) is interpretable as the relative welfare weight that the government gives to the utility of high-ability individuals. Since this redistribution is based on ability-type-specific lump-sum taxes, there is no redistributive reason to distort the labor supply behavior. Second, the environmental externality is fully internalized by a Pigouvian tax on the dirty good, $t_{x}=\sum_{j} M W P_{E, b}^{j}$, reflecting the sum of all individuals' marginal willingness to pay for an individual to reduce his/her consumption of the dirty good. Therefore, there is no corrective reason to distort the consumption of other goods or the labor supply, implying that the commodity tax on the non-numeraire clean good as well as the marginal income tax rates are zero.

\footnotetext{
${ }^{9}$ All results in this section are special cases of the results derived in Section 3, where we explain the underlying calculations in greater detail.
} 


\section{Second-Best Taxation in the Benchmark Model}

Let us now add the assumption that innate earnings-ability (as measured by the before-tax wage rate) is private information. ${ }^{10}$ This implies that the government observes the before-tax income of each agent $\left(w^{j} l^{j}\right)$ but that the individual's productivity level $w^{j}$ (and, therefore, also the hours of work) is private information. Consequently, the government can no longer differentiate taxes by ability; it must, instead, base its redistribution policy on the observable income. This necessitates, in turn, that the tax policy satisfies self-selection constraints, such that each individual prefers the allocation intended for his/her type to the allocation intended for the other type. Without this type of restriction, individuals may engage in mimicking, which would undermine the redistribution system. We focus on the normal case where the government wants to redistribute income from the high-ability type to the low-ability type, in which high-ability individuals may benefit from the redistribution policy by mimicking the low-ability type. Therefore, to prevent the high-ability type from mimicking the low-ability type, we impose the following self-selection constraint: ${ }^{11}$

$$
v^{2}=v\left(b^{2}, q_{x}, q_{y}, z^{2}, E\right) \geq v\left(b^{1}, q_{x}, q_{y}, \hat{z}^{2}, E\right)=\hat{v}^{2} .
$$

The left hand side of the weak inequality denotes the utility of the high-ability type, and the right hand side the utility of the mimicker. The mimicker is a high-ability individual who pretends to be a low-ability type by reporting the same labor income (and thus receiving the same disposable income) as the low-ability type. The variable $\hat{v}^{2}$ denotes the utility of the mimicker. Note that such mimicking is perfectly possible without the self-selection constraint: if a high-ability individual would gain from pretending to be a low-ability type, all he/she would have to do is to reduce the hours of work in order to reach the same before-tax income as the low-ability type. The variable $\hat{z}^{2}=h-\phi l^{1}$ is the time spent on leisure by the mimicker, where $\phi=w^{1} / w^{2}<1$ denotes the relative wage rate, and $\phi l^{1}$ denotes the number of work hours the mimicker would need to supply in order to reach the low-ability type's before-tax income. Furthermore, we

\footnotetext{
${ }^{10}$ The model examined in this section is a slightly modified version of the model used in Pirttilä and Tuomala (1997).

${ }^{11}$ The other possible self-selection constraint, which serves to prevent low-ability individuals from mimicking the high-ability type, will not be binding under the assumed redistribution profile. To avoid unnecessary notation, we ignore this constraint in what follows.
} 
assume that the government does not observe the consumption behavior at the individual level; only the aggregate consumption of each good, which rules out individual-specific commodity taxes.

Adding the self-selection constraint to equation (7) means that the Lagrangean of the social decision-problem changes to read

$$
L=v^{1}+\eta\left(v^{2}-\bar{v}^{2}\right)+\lambda\left(v^{2}-\hat{v}^{2}\right)+\mu\left(E-\sum_{j} x^{j}\right)+\gamma \sum_{j}\left(w^{j} l^{j}-b^{j}+t_{x} x^{j}+t_{y} y^{j}\right)
$$

where $\lambda$ denotes the Lagrange multiplier associated with the self-selection constraint. The other aspects of the model (including the choices made by private agents) are the same as before. The social first-order conditions for $b^{1}, l^{1}, b^{2}, l^{2}, t_{x}, t_{y}$, and $E$ can now be written as follows:

$$
\begin{aligned}
& \frac{\partial L}{\partial b^{1}}=v_{b}^{1}-\lambda \hat{v}_{b}^{2}+\gamma\left(t_{x} \frac{\partial x^{1}}{\partial b^{1}}+t_{y} \frac{\partial y^{1}}{\partial b^{1}}-1\right)-\mu \frac{\partial x^{1}}{\partial b^{1}}=0 \\
& \frac{\partial L}{\partial l^{1}}=-v_{z}^{1}+\lambda \phi \hat{v}_{z}^{2}+\gamma\left(w^{1}-t_{x} \frac{\partial x^{1}}{\partial z^{1}}-t_{y} \frac{\partial y^{1}}{\partial z^{1}}\right)+\mu \frac{\partial x^{1}}{\partial z^{1}}=0 \\
& \frac{\partial L}{\partial b^{2}}=(\eta+\lambda) v_{b}^{2}+\gamma\left(t_{x} \frac{\partial x^{2}}{\partial b^{2}}+t_{y} \frac{\partial y^{2}}{\partial b^{2}}-1\right)-\mu \frac{\partial x^{2}}{\partial b^{2}}=0 \\
& \frac{\partial L}{\partial l^{2}}=-(\eta+\lambda) v_{z}^{2}+\gamma\left(w^{2}-t_{x} \frac{\partial x^{2}}{\partial z^{2}}-t_{y} \frac{\partial y^{2}}{\partial z^{2}}\right)+\mu \frac{\partial x^{2}}{\partial z^{2}}=0 \\
& \frac{\partial L}{\partial t_{x}}=\left(\gamma-v_{b}^{1}\right) x^{1}+\left[\gamma-(\eta+\lambda) v_{b}^{2}\right] x^{2}+\lambda \hat{v}_{b}^{2} \hat{x}^{2}+\gamma\left(t_{x}-\frac{\mu}{\gamma}\right) \sum_{j} \frac{\partial x^{j}}{\partial q_{x}}+\gamma t_{y} \sum_{j} \frac{\partial y^{j}}{\partial q_{x}}=0 \\
& \frac{\partial L}{\partial t_{y}}=\left(\gamma-v_{b}^{1}\right) y^{1}+\left[\gamma-(\eta+\lambda) v_{b}^{2}\right] y^{2}+\lambda \hat{v}_{b}^{2} \hat{y}^{2}+\gamma\left(t_{x}-\frac{\mu}{\gamma}\right) \sum_{j} \frac{\partial x^{j}}{\partial q_{y}}+\gamma t_{y} \sum_{j} \frac{\partial y^{j}}{\partial q_{y}}=0 \\
& \frac{\partial L}{\partial E}=v_{E}^{1}+(\eta+\lambda) v_{E}^{2}-\lambda \hat{v}_{E}^{2}+\mu+\gamma\left(t_{x}-\frac{\mu}{\gamma}\right) \sum_{j} \frac{\partial x^{j}}{\partial E}+\gamma t_{y} \sum_{j} \frac{\partial y^{j}}{\partial E}=0
\end{aligned}
$$

where subscripts attached to the conditional indirect utility function denote partial derivatives (as before). We have used Roy's identity in equations (11e) and (11f). ${ }^{12}$

The efficient tax structure implied by these first-order conditions will depend on the social shadow price of the environmental damage measured in terms of public funds, as defined by the quotient of Lagrange multipliers $\mu / \gamma$. This ratio is interpretable as the value the government attaches to reduced environmental damage measured in terms of tax revenue. We start by

\footnotetext{
${ }^{12}$ More specifically, we have used $v_{t_{x}}^{j}=-v_{b}^{j} x^{j}$ and $v_{t_{y}}^{j}=-v_{b}^{j} y^{j}$.
} 
presenting an analogue to the conditional shadow price derived by Pirttilä and Tuomala (1997), where $\mu / \gamma$ is defined conditional on the commodity taxes. An unconditional measure will be derived and discussed later. By using $M W P_{E, b}^{j}=-v_{E}^{j} / v_{b}^{j}$ (as defined above) and $\widehat{M W P}_{E, b}^{2}=$ $-\hat{v}_{E}^{2} / \hat{v}_{b}^{2}$, we show in the Appendix that the conditional shadow price can be written as follows:

$$
\frac{\mu}{\gamma}=\sigma\left[\sum_{j} M W P_{E, b}^{j}+\lambda^{*}\left(M W P_{E, b}^{1}-\widehat{M W P}_{E, b}^{2}\right)-\sum_{j} t_{x} \frac{\partial \tilde{x}^{j}}{\partial E}-\sum_{j} t_{y} \frac{\partial \tilde{y}^{j}}{\partial E}\right]
$$

where $\lambda^{*}=\lambda \hat{v}_{b}^{2} / \gamma$ and

$$
\frac{1}{\sigma}=1-\frac{\partial \tilde{x}^{1}}{\partial E}-\frac{\partial \tilde{x}^{2}}{\partial E}, \quad \frac{\partial \tilde{x}^{j}}{\partial E}=\frac{\partial x^{j}}{\partial E}+\frac{\partial x^{j}}{\partial b^{j}} M W P_{E, b}^{j}, \quad \frac{\partial \tilde{y}^{j}}{\partial E}=\frac{\partial y^{j}}{\partial E}+\frac{\partial y^{j}}{\partial b^{j}} M W P_{E, b}^{j} .
$$

The variable $\sigma$ is commonly referred to as the environmental feedback parameter, while the second and third equations in (13) measure how the compensated conditional demand for the dirty good and non-numeraire clean good, respectively, respond to increased environmental damage.

Equation (12) shows that the social value of a decrease in the level of environmental damage, $E$, is decomposable into four basic components: (i) the feedback effect, (ii) the sum of the consumers' marginal willingness to pay for a cleaner environment, (iii) a component measuring how the low-ability type and the mimicker differ in their marginal valuation of a cleaner environment, and (iv) tax revenue effects due to that $E$ influences the commodity tax bases. In the first-best (full information) setting briefly examined in Section 2, only component (ii) was present and formed the basis for the Pigouvian commodity tax on the dirty good.

The feedback parameter (component [i] above) captures that a change in the externality feeds back into the demand equations. Albeit in a different context, Sandmo (1980) shows that $\sigma$ must be positive to ensure stability. Component (iii) is due to the self-selection constraint (and is proportional to the Lagrange multiplier attached to this constraint). As such, it is fundamentally related to the assumption of asymmetric information: it would vanish in a first-best setting where $\lambda=0$. This component arises because the government may relax the self-selection constraint by exploiting that the mimicker and the low-ability type typically differ with respect to the marginal willingness to pay for a cleaner environment. In our framework, where all individuals share a 
common utility function, the only difference between the mimicker and the low-ability type is that the mimicker spends more time on leisure (due to that the mimicker is more productive than the low-ability type). Therefore, the sign of the variable $M W P_{E, b}^{1}-\widehat{M W P}_{E, b}^{2}$ depends on whether leisure is complementary with, or substitutable for, environmental quality.

If leisure and environmental quality are complements in the sense that the marginal willingness to pay for a decrease in the environmental damage increases with the time spent on leisure, then $M W P_{E, b}^{1}<\widehat{M W P_{E, b}^{2}}$. In this case, therefore, an increase in the level of environmental damage leads to a larger utility loss for the mimicker than for the low-ability type, which contributes to relax the self-selection constraint (and thus creates room for more redistribution). ${ }^{13}$ This explains why the government attaches a lower marginal value to environmental quality than it would otherwise have done. The opposite reasoning applies if leisure and environmental quality are substitutes such that $M W P_{E, b}^{1}>\widehat{M W P}_{E, b}^{2}$ : a decrease in $E$ would, in this case, contribute to a relaxation of the self-selection constraint, which leads the government to attach a higher marginal value to environmental quality than it would otherwise have done. Note finally that the second term on the right hand side will vanish from equation (12) if leisure is weakly separable from the other goods in terms of the utility function, since the low-ability type and the mimicker will, in this case, attach the same marginal value to environmental quality, i.e., $M W P_{E, b}^{1}=\widehat{M W P}_{E, b}^{2}$.

The tax revenue effects of increased environmental damage (referred to as component [iv] above) are summarized by the final two terms in square brackets on the right hand side of equation (12). These are similar to the tax revenue effects of public good provision discussed by Atkinson and Stern (1974). We will return to these effects below.

Let us now turn to commodity taxation. We show in the Appendix that the system of commodity taxes takes the following form:

$$
\begin{aligned}
& t_{x}=\lambda^{*}\left(x^{1}-\hat{x}^{2}\right) \frac{\sum_{j} \partial \tilde{y}^{j} / \partial q_{y}}{\Omega}-\lambda^{*}\left(y^{1}-\hat{y}^{2}\right) \frac{\sum_{j} \partial \tilde{y}^{j} / \partial q_{x}}{\Omega}+\frac{\mu}{\gamma} \\
& t_{y}=\lambda^{*}\left(y^{1}-\hat{y}^{2}\right) \frac{\sum_{j} \partial \tilde{x}^{j} / \partial q_{x}}{\Omega}-\lambda^{*}\left(x^{1}-\hat{x}^{2}\right) \frac{\sum_{j} \partial \tilde{x}^{j} / \partial q_{y}}{\Omega}
\end{aligned}
$$

${ }^{13}$ This is socially desirable because a binding self-selection constraint prevents the government from reaching its most preferred redistribution. 
where $\Omega=\sum_{j} \frac{\partial \tilde{x}^{j}}{\partial q_{x}} \sum_{j} \frac{\partial \tilde{y}^{j}}{\partial q_{y}}-\sum_{j} \frac{\partial \tilde{x}^{j}}{\partial q_{y}} \sum_{j} \frac{\partial \tilde{y}^{j}}{\partial q_{x}}$ and

$$
\frac{\partial \tilde{x}^{j}}{\partial q_{x}}=\frac{\partial x^{j}}{\partial q_{x}}+\frac{\partial x^{j}}{\partial b^{j}} x^{j}, \quad \frac{\partial \tilde{x}^{j}}{\partial q_{y}}=\frac{\partial x^{j}}{\partial q_{y}}+\frac{\partial x^{j}}{\partial b^{j}} y^{j}, \quad \frac{\partial \tilde{y}^{j}}{\partial q_{x}}=\frac{\partial y^{j}}{\partial q_{x}}+\frac{\partial y^{j}}{\partial b^{j}} x^{j}, \quad \frac{\partial \tilde{y}^{j}}{\partial q_{y}}=\frac{\partial y^{j}}{\partial q_{y}}+\frac{\partial y^{j}}{\partial b^{j}} y^{j}
$$

The expressions in (15) are price effects on the conditional compensated demand functions based on the Slutsky condition. We can also see that $\Omega>0$ as long as the negative compensated own price effects dominate the cross-price effects, which will be assumed in what follows.

Equations (14a) and (14b) reflect two different motives for commodity taxation: (i) to relax the self-selection constraint and (ii) to adjust the level of the environmental damage. The first motive is independent of $\mu / \gamma$ and is reflected in the terms proportional to $x^{1}-\hat{x}^{2}$ and $y^{1}-\hat{y}^{2}$, respectively. As such, this policy incentive would be present also in the absence of any environmental externality. Although the low-ability type and the mimicker have the same disposable income (and thus the same consumption possibility), they may still choose different consumption bundles. The reason is that the consumption pattern may correlate with the use of leisure. Consider the first term of the right hand side of equation (14a). If leisure is complementary with the dirty good such that the mimicker consumes more of this good than the low-ability type, i.e. if $x^{1}<\hat{x}^{2}$, a higher tax on the dirty good would for this reason hurt the mimicker more than it hurts the low-ability type. As such, the government has an incentive to relax the self-selection constraint by implementing a higher tax on the dirty good than it would otherwise have done. ${ }^{14}$ The analogous argument for a lower tax on the dirty good follows if $x^{1}>\hat{x}^{2}$. The other terms proportional to $x^{1}-\hat{x}^{2}$ and $y^{1}-\hat{y}^{2}$ are interpretable in the same general way. Note also that these terms would all vanish in the special case where leisure is weakly separable from the other goods in the utility function, in which the low-ability type and the mimicker would choose the same consumption bundle such that $x^{1}=\hat{x}^{2}$ and $y^{1}=\hat{y}^{2}$.

The policy incentive to adjust the level of environmental damage is captured by the third term on the right hand side of equation (14a), i.e., $\mu / \gamma$. Yet, recall from the discussion of equation (12) above that $\mu / \gamma$ reflects a mixture of corrective and redistributive motives for influencing the level of environmental damage. A decrease in $E$ does not only affect welfare by lowering the disutility

\footnotetext{
${ }^{14}$ Note that $\partial \tilde{y}^{j} / \partial q_{y}<0$ for $j=1,2$.
} 
of environmental damage; it may also either relax or tighten the self-selection constraint depending on whether the marginal willingness to pay for a cleaner environment decreases or increases with the time spent on leisure. Despite this broader motive for influencing $E$, a key result is, nevertheless, that the commodity tax structure satisfies Sandmo's (1975) additivity property (as it also did in the first best setting examined in the previous section). This is seen from equations (14), where the social shadow price of the environmental damage enters additively in the policy rule for the tax on the dirty good, while it does not directly affect the policy rule for the tax on the non-numeraire clean good. This does not mean that the level of $t_{y}$ is independent of the social value of a cleaner environment. ${ }^{15}$ It just means that the policy rule for $t_{y}$ takes the same form as in the absence of any externality. Finally, for the principle of targeting to be fully applicable, it remains to show that the policy rules for marginal income taxation do not depend directly on $\mu / \gamma$; an issue to which we return below.

By substituting equations (14a) and (14b) into equation (12), an "unconditional" formulation of the social shadow price of environmental damage emerges

$$
\begin{aligned}
\frac{\mu}{\gamma} & =\sum_{j=1}^{2} M W P_{E, b}^{j}+\lambda^{*}\left(M W P_{E, b}^{1}-\widehat{M W P_{E, b}^{2}}\right) \\
& -\lambda^{*}\left(x^{1}-\hat{x}^{2}\right) \frac{\sum_{j} \frac{\partial \tilde{y}^{j}}{\partial q_{y}}}{\Omega} \sum_{j=1}^{2} \frac{\partial \tilde{x}^{j}}{\partial E}+\lambda^{*}\left(y^{1}-\hat{y}^{2}\right) \frac{\sum_{j} \frac{\partial \widetilde{y}^{j}}{\partial q_{x}}}{\Omega} \sum_{j=1}^{2} \frac{\partial \tilde{x}^{j}}{\partial E} \\
& -\lambda^{*}\left(y^{1}-\hat{y}^{2}\right) \frac{\sum_{j} \frac{\partial \tilde{x}^{j}}{\partial q_{x}}}{\Omega} \sum_{j=1}^{2} \frac{\partial \tilde{y}^{j}}{\partial E}+\lambda^{*}\left(x^{1}-\hat{x}^{2}\right) \frac{\sum_{j} \frac{\partial \tilde{x}^{j}}{\partial q_{y}}}{\Omega} \sum_{j=1}^{2} \frac{\partial \tilde{y}^{j}}{\partial E}
\end{aligned}
$$

Two things are worth noticing. First, the feedback effect parameter, $\sigma$, vanishes here, where the social shadow price is no longer conditioned on the effect of $E$ on the tax revenue from commodity taxation. Second, the "tax revenue effect" discussed above is driven by an incentive to relax the self-selection constraint, by exploiting that the consumption bundle preferred by the low-ability type typically differs from the bundle preferred by the mimicker. We described this mechanism in the context of the commodity tax structure in equations (14a) and (14b), and it now re-appears in the second and third rows of equation (12'). In other words, the desire to relax the self-selection constraint explains why the tax revenue effect is present here, while it was absent in the first-best policy characterized in Section 2 (where the sole purpose of commodity taxation

\footnotetext{
${ }^{15}$ Note that equations (14) are not reduced forms.
} 
was to internalize the externality). To illustrate how this mechanism works in the shadow price formula, let us assume that leisure and the dirty good are complementary such that $x^{1}<\hat{x}^{2}$, which provides an incentive to relax the self-selection constraint through a higher commodity tax on the dirty good, ceteris paribus. This effect is captured by the first term on the right hand side of equation (14a). The same term re-appears in the second row of the unconditional shadow price formula in equation (12') and contributes to decrease (increase) $\mu / \gamma$ if $\sum_{j} \tilde{x}^{j}$ increases (decreases) in $E$. The intuition is that more tax revenue increases the maneuver space for the government when the self-selection constraint binds. The other terms in the second and third row of equation (12') are interpretable in the same general way.

We mentioned above that a binding self-selection constraint limits the scope for redistribution which, in turn, creates an incentive to adjust the tax policy in order to relax this constraint. To illustrate the key mechanism at work, let us simplify by considering the special case where leisure is weakly separable from the other goods in the utility function, which means that $x^{1}=$ $\hat{x}^{2}, y^{1}=\hat{y}^{2}$, and $M W P_{E, b}^{1}=\widehat{M W P}_{E, b}^{2}$. Equations (14) then imply $t_{x}=\mu / \gamma=\sum_{j} M W P_{E, b}^{j}$ and $t_{y}=0$. In this special case, therefore, the second-best optimal commodity tax policy coincides with the first-best policy rules for commodity taxation presented in Section 2. However, as long as the self-selection constraint is binding, we can, nevertheless, use these simplified commodity tax formulas in combination with equations (11a) and (11b) to derive $v_{b}^{1}-\lambda \hat{v}_{b}^{2}-\lambda v_{b}^{2}=\eta v_{b}^{2}$. Hence, $v_{b}^{1}>\eta v_{b}^{2}$ from which we may conclude that a binding self-selection constraint leads to over-taxation of the low-ability type and under-taxation of the high-ability type compared to the first-best resource allocation. The intuition is that the self-selection constraint imposes a restriction on the amount of resources that the government can redistribute from the high-ability to the low-ability type without undermining the redistribution system.

What does the second-best efficient resource allocation satisfying equations (11) imply for marginal income taxation? Let $M R S_{z, b}^{j}=v_{z}^{j} / v_{b}^{j}$ (for $\left.j=1,2\right)$ and $\widehat{M R S}_{z, b}^{2}=\hat{v}_{z}^{2} / \hat{v}_{b}^{2}$ denote the marginal rate of substitution between leisure and private disposable income for ability-type $j$ and the mimicker, respectively. To simplify the presentation, we use the following notation for how increased leisure time affects the conditional compensated commodity demand: 


$$
\frac{\partial \tilde{x}^{j}}{\partial z^{j}}=\frac{\partial x^{j}}{\partial z^{j}}-\frac{\partial x^{j}}{\partial b^{j}} M R S_{z, b}^{j}, \quad \frac{\partial \tilde{y}^{j}}{\partial z^{j}}=\frac{\partial y^{j}}{\partial z^{j}}-\frac{\partial y^{j}}{\partial b^{j}} M R S_{z, b}^{j}
$$

We show in the Appendix that the marginal income taxes can then be written as follows: ${ }^{16}$

$$
\begin{aligned}
T_{I}^{1} & =\frac{\lambda^{*}}{w^{1}}\left(M R S_{z, b}^{1}-\phi \widehat{M R S}_{z, b}^{2}\right)+\left(t_{x}-\frac{\mu}{\gamma}\right) \frac{1}{w^{1}} \frac{\partial \tilde{x}^{1}}{\partial z^{1}}+t_{y} \frac{1}{w^{1}} \frac{\partial \tilde{y}^{1}}{\partial z^{1}} \\
T_{I}^{2} & =\left(t_{x}-\frac{\mu}{\gamma}\right) \frac{1}{w^{2}} \frac{\partial \tilde{x}^{2}}{\partial z^{2}}+t_{y} \frac{1}{w^{2}} \frac{\partial \tilde{y}^{2}}{\partial z^{2}}
\end{aligned}
$$

Before interpreting equations (17a) and (17b), let us rewrite equation (14a) to obtain an expression for $t_{x}-\mu / \gamma$

$$
t_{x}-\frac{\mu}{\gamma}=\lambda^{*}\left(x^{1}-\hat{x}^{2}\right) \frac{\sum_{j} \partial \tilde{y}^{j} / \partial q_{y}}{\Omega}-\lambda^{*}\left(y^{1}-\hat{y}^{2}\right) \frac{\sum_{j} \partial \tilde{y}^{j} / \partial q_{x}}{\Omega} .
$$

From (17a), (17b) and (14a') we can conclude that the government has two basic motives to influence the hours of work: (1) to relax the self-selection constraint and (2) to compensate the consumers for the distortions created by the commodity taxes. Since the government can use the commodity tax on the dirty good, $t_{x}$, to target the environmental damage, there is no incentive to distort the labor supply behavior in response to the externality. In other words, equation (14a') means that $\mu / \gamma$ vanishes from the policy rules given in equations (17a) and (17b). This is, of course, also a consequence of the principle of targeting.

To interpret equations (17a) and (17b), consider first the special case without commodity taxes and without the environmental externality, i.e., where $t_{x}=t_{y}=\mu / \gamma=0$. In this case, equations (17a) and (17b) coincide with the marginal income tax formulas derived by Stiglitz (1982), where the government implements a positive marginal labor income tax for the low-ability type and a zero marginal income tax for the high-ability type. The intuition is that we can relax the selfselection constraint by taxing the mimicked agent at the margin (which makes mimicking less attractive). ${ }^{17}$ This is so because a potential mimicker attaches a lower marginal value to leisure (and is thus hurt more by being forced to spend more time on leisure instead of earning income) than the low-ability type.

\footnotetext{
16 This way of writing the marginal income tax formulas originates from Aronsson, Jonsson, and Sjögren (2006).

${ }^{17}$ Note once again that this refers to marginal taxation. Redistribution from the high-ability to the low-ability type implies $T\left(I^{1}\right)<T\left(I^{2}\right)$ at the second-best optimum, i.e., the income tax payment made by the high-ability type exceeds the payment made by the low-ability type.
} 
Returning to the actual marginal income tax structure derived above, the final two terms on the right hand side of equation (17a), and the analogous two terms on the right hand side of equation (17b), are interpretable as interaction effects between marginal income and commodity taxation. These effects arise because the government uses the (flexible) income tax to compensate the consumers for distortions created by the (less flexible) commodity taxes. To see this more clearly, note that the government has no direct motive besides externality-correction to affect the consumption of the dirty good. Therefore, if $t_{x} \neq \mu / \gamma$ at the optimum, the government may use marginal income taxation to compensate the consumers for the distortionary effect caused by $t_{x}$. If $t_{x}>\mu / \gamma$, the commodity tax on the dirty good is interpretable as being too high from the perspective of externality correction, in which case it is welfare improving to stimulate the consumption of the dirty good. This provides an incentive for the government to implement a higher marginal income tax rate if leisure is complementary with the dirty good $\left(\partial \tilde{x}^{j} / \partial z^{j}>0\right)$, and a lower marginal income tax rate if leisure is substitutable for the dirty good $\left(\partial \tilde{x}^{j} / \partial z^{j}<0\right)$, ceteris paribus. Policy incentives opposite to those just described surface if $t_{x}<\mu / \gamma$, meaning that the government may use the income tax to reduce the consumption of the dirty good. By a similar argument, we can interpret the term proportional to $t_{y}$ in equations (17a) and (17b) as an incentive to offset the distortion created by the commodity tax on the non-numeraire clean good, by exploiting the relationship between the consumption of this good and the time spent on leisure.

We have followed Sandmo (1975) and Pirttilä and Tuomala (1997) in assuming that the externality is generated through the consumption of dirty goods. An alternative approach, explored by Cremer and Gahvari (2001), would be to assume that the externalities are generated in production - through the release of emissions - instead of in consumption. They consider an extension of the mixed tax problem under asymmetric information, where the government has access to an emission tax in addition to the income and commodity taxes. If this emission tax is flexible enough to allow the government to exercise perfect control over emissions, it follows that the emission tax will be a perfect instrument for correction. Therefore, the principle of targeting applies, meaning that the government uses the emission tax to correct for the externality, whereas the policy rules for commodity taxation and marginal income taxation take the same form as in 
the absence of any externalities. Furthermore, the corrective component of the emission tax does not only reflect the consumers' marginal willingness to pay to avoid the externality; it also reflects the self-selection constraints (via differences in the marginal valuation of a cleaner environment between mimickers and mimicked agents) as well as tax base effects. As such, this corrective tax component bears a close resemblance to equation (12) above.

\section{Two Extensions of the Benchmark Model}

In this section, we consider two extensions of the benchmark model set out above: (i) a nonatmospheric environmental externality and (ii) border trade in the externality generating good. Both extensions are empirically relevant and will change the results derived so far in fundamental ways.

\subsection{A Non-Atmospheric Externality}

In the reference model analyzed in Sections 2 and 3, each individual contributes equally much to the environmental damage at the margin. We referred to this externality as atmospheric. Another possibility is that the externality is non-atmospheric such that the marginal contribution to the externality differs between individuals. ${ }^{18}$ One example would be different types of air-pollution, where the marginal damage increases with the local concentration in the atmosphere, in which case one may expect the marginal damage to be sensitive to where the emissions are released (this may apply to pollutants such as sulfur dioxide and nitrogen dioxide). ${ }^{19}$ Another example could be waste separation. If the waste of a dirty good is properly treated, then the environmental damage is minimized and this occurs if the waste of the dirty good is sorted into the proper waste bin. However, if the waste of the dirty good instead ends up in the wrong waste bin, this waste is not properly treated and the environmental damage is larger. If the agents differ in the degree by which they properly sort waste, the individual contributions to the environmental damage will differ at the margin. ${ }^{20}$

\footnotetext{
${ }^{18}$ See Diamond (1973) for an early contribution to the literature on tax policy responses to non-atmospheric externalities. See also, e.g., Aronsson and Johansson-Stenman (2010) and Eckerstorfer and Wendner (2013), where non-atmospheric consumption externalities are integrated into models of optimal redistributive taxation.

${ }^{19}$ See Montgomery (1972) for an early study on cost efficient environmental policy in this context.

${ }^{20}$ This exemplifies a case where the externality is generated in the consumption process and not by the consumption itself (c.f. Sandmo, 1976).
} 
To incorporate this feature into the model in the simplest possible way, we just assume that the two ability-types differ in their marginal contributions to the externality and rewrite the equation for the environmental externality to read

$$
E=\alpha^{1} x^{1}+\alpha^{2} x^{2}
$$

Following Eckerstorfer and Wendner (2013), the externality is said to be non-atmospheric if the damage-weights differ across agents, i.e., if $\alpha^{1} \neq \alpha^{2}$, whereas an externality is said to be atmospheric if the weights are equal across all agents. Except that equation (18) now replaces the constraint $E=x^{1}+x^{2}$ used in Sections 2 and 3, the model takes the same form as before. Furthermore, all commodity and marginal income tax formulas presented below are derived in the same general way as in Section 3. To avoid unnecessary repetition, we refrain from presenting the underlying private and social decision-problems here.

For purposes of interpretation, it is convenient to begin by characterizing the commodity tax structure in a hypothetical scenario where type-specific commodity taxes are available. ${ }^{21}$ If we denote the type-specific commodity taxes facing ability-type $j$ by $t_{x}^{j}$ and $t_{y}^{j}$, respectively, and rewrite the government's budget constraint to read $\sum_{j}\left(w^{j} l^{j}-b^{j}+t_{x}^{j} x^{j}+t_{y}^{j} y^{j}\right)=0$, it is straightforward to show that the solution would feature the following type-specific commodity taxes:

$$
\begin{aligned}
t_{x}^{1} & =\lambda^{*}\left(x^{1}-\hat{x}^{2}\right) \frac{\partial \tilde{y}^{1} / \partial q_{y}^{1}}{\Omega_{1}}-\lambda^{*}\left(y^{1}-\hat{y}^{2}\right) \frac{\partial \tilde{y}^{1} / \partial q_{x}^{1}}{\Omega_{1}}+\alpha^{1} \frac{\mu}{\gamma} \\
t_{y}^{1} & =\lambda^{*}\left(y^{1}-\hat{y}^{2}\right) \frac{\partial \tilde{x}^{1} / \partial q_{x}^{1}}{\Omega_{1}}-\lambda^{*}\left(x^{1}-\hat{x}^{2}\right) \frac{\partial \tilde{x}^{1} / \partial q_{y}^{1}}{\Omega_{1}} \\
t_{x}^{2} & =\alpha^{2} \frac{\mu}{\gamma} \\
t_{y}^{2} & =0
\end{aligned}
$$

where $q_{x}^{j}=p_{x}+t_{x}^{j}, q_{y}^{j}=p_{y}+t_{y}^{j}$ and $\Omega_{1}=\frac{\partial \tilde{x}^{1}}{\partial q_{x}^{1}} \frac{\partial \tilde{y}^{1}}{\partial q_{y}^{1}}-\frac{\partial \tilde{x}^{1}}{\partial q_{y}^{1}} \frac{\partial \tilde{y}^{1}}{\partial q_{x}^{1}}$

\footnotetext{
${ }^{21}$ Recall that our earlier assumptions rule out individual-specific commodity taxes. Yet, it is not always unrealistic to allow the commodity taxes to differ between individuals, since the consumption of certain goods is observable at the individual level (e.g., homes and cars).
} 
The social shadow price of the environmental damage, $\mu / \gamma$, takes the same form as in equation (12) in Section 3, with the exception that the feedback parameter is slightly different here. ${ }^{22}$ The tax formulas in (19) reveal two important insights. First, if type-specific commodity taxes were available, the self-selection motive for implementing a non-zero commodity tax (as reflected in the first two terms on the right hand side of equations ([19a] and [19b]) would only apply in the tax formulas for the low-ability type. ${ }^{23}$ This is analogous to results derived in the literature on optimal nonlinear income taxation, where the incentive to relax the self-selection constraint motivates a distortion imposed on the mimicked agent (the low-ability type). Second, the part of the commodity tax formula that is associated with externality correction is scaled by the marginal damage implied by each type's consumption, $\alpha^{j}$. The latter result implies that the externality correcting part of the type-specific commodity tax differs between agent types if $\alpha^{1} \neq \alpha^{2}$.

Let us now return to the outcome of the actual policy problem, where each commodity tax must be paid at the same rate by everybody. The second-best efficient commodity tax structure can then be summarized as follows: ${ }^{24}$

$$
\begin{aligned}
t_{x} & =\lambda^{*}\left(x^{1}-\hat{x}^{2}\right) \frac{\sum_{j} \partial \tilde{y}^{j} / \partial q_{y}}{\Omega}-\lambda^{*}\left(y^{1}-\hat{y}^{2}\right) \frac{\sum_{j} \partial \tilde{y}^{j} / \partial q_{x}}{\Omega}+\frac{\mu}{\gamma}\left(\alpha^{1} \theta^{1}+\alpha^{2} \theta^{2}\right) \\
t_{y} & =\lambda^{*}\left(y^{1}-\hat{y}^{2}\right) \frac{\sum_{j} \partial \tilde{x}^{j} / \partial q_{x}}{\Omega}-\lambda^{*}\left(x^{1}-\hat{x}^{2}\right) \frac{\sum_{j} \partial \tilde{x}^{j} / \partial q_{y}}{\Omega} \\
& +\frac{\mu}{\gamma}\left[\left(\alpha^{1}-\alpha^{2}\right) \frac{\partial \tilde{x}^{2} / \partial q_{x}}{\Omega} \frac{\partial \tilde{x}^{1}}{\partial q_{y}}+\left(\alpha^{2}-\alpha^{1}\right) \frac{\partial \tilde{x}^{1} / \partial q_{x}}{\Omega} \frac{\partial \tilde{x}^{2}}{\partial q_{y}}\right]
\end{aligned}
$$

where

$$
\theta^{1}=\frac{\frac{\partial \widetilde{x}^{1}}{\partial q_{x}} \sum_{j} \frac{\partial \widetilde{y}^{j}}{\partial q_{y}}-\frac{\partial \widetilde{x}^{1}}{\partial q_{y}} \sum_{j} \frac{\partial \widetilde{y}^{j}}{\partial q_{x}}}{\Omega} \quad \text { and } \quad \theta^{2}=\frac{\frac{\partial \widetilde{x}^{2}}{\partial q_{x}} \sum_{j} \frac{\partial \widetilde{y}^{j}}{\partial q_{y}}-\frac{\partial \widetilde{x}^{2}}{\partial q_{y}} \sum_{j} \frac{\partial \widetilde{y}^{j}}{\partial q_{x}}}{\Omega}
$$

${ }^{22}$ The analogue to the feedback effect in (13) is given by

$$
\frac{1}{\sigma}=1-a^{1} \frac{\partial \tilde{x}^{1}}{\partial E}-a^{2} \frac{\partial \tilde{x}^{2}}{\partial E}
$$

${ }^{23}$ This result would also hold in the reference model presented in Section 3 if type-specific commodity taxes were available.

${ }^{24}$ To derive equations (20a) and (20b), we use the same approach as when deriving equations (14a) and (14b). The only difference is that the externality is non-atmospheric here and given in equation (18). 
and where we use that $\Omega$ (which was defined in Section 3) can be written as

$$
\Omega=\left(\frac{\partial \tilde{x}^{1}}{\partial q_{x}} \sum_{j} \frac{\partial \tilde{y}^{j}}{\partial q_{y}}-\frac{\partial \tilde{x}^{1}}{\partial q_{y}} \sum_{j} \frac{\partial \tilde{y}^{j}}{\partial q_{x}}\right)+\left(\frac{\partial \tilde{x}^{2}}{\partial q_{x}} \sum_{j} \frac{\partial \tilde{y}^{j}}{\partial q_{y}}-\frac{\partial \tilde{x}^{2}}{\partial q_{y}} \sum_{j} \frac{\partial \tilde{y}^{j}}{\partial q_{x}}\right)
$$

This means, in turn, that $\theta^{1}+\theta^{2}=1$. The first two terms on the right hand side of equations (20a) and (20b) are analogous to their counterparts in equations (14a) and (14b), which were discussed at some length in Section 3.

The novelty here is the third term on the right hand side of each tax formula, showing how the social shadow price of the environmental damage, $\mu / \gamma$, affects the optimal policy rules for commodity taxation. From equation (20a), we see that the corrective part of the commodity tax on the dirty good is a weighted average of the social marginal damage generated by each abilitytype's consumption of the dirty good, i.e., a weighted average of $\alpha^{1} \mu / \gamma$ and $\alpha^{2} \mu / \gamma$. Another interpretation is that the corrective part of the commodity tax on the dirty good is a weighted average of the corrective components included in the hypothetical, type-specific commodity taxes in equations (19a) and (19c). In the special case where the externality is atmospheric such that $\alpha^{1}=\alpha^{2}$, equations (20a) and (20b) coincide with the commodity tax formulas in the benchmark model given by equations (14a) and (14b).

However, if the externality is non-atmospheric, i.e., $\alpha^{1} \neq \alpha^{2}$, a linear tax on the dirty good is not a sufficiently flexible instrument for internalizing the externalities. In turn, this will have implications for the optimal taxation of the clean non-numeraire good and for the marginal income tax rates. If $\alpha^{1}>\alpha^{2}$, the corrective part of $t_{x}$ in equation (20a) falls short of the value of the marginal externality generated by the low-ability type and exceeds the value of the marginal externality generated by the high-ability type. From the perspective of externality correction, therefore, the low-ability type consumes more of the dirty good than preferred by the government. This provides an incentive for the government to use the tax on the non-numeraire clean good as an indirect instrument for externality correction by reducing the low-ability type's consumption of the dirty good. Therefore, if the non-numeraire clean good and the dirty good are substitutes (complements) in the sense that the compensated cross-price effect, $\partial \tilde{x}^{1} / \partial q_{y}$, is positive (negative), the government will choose a lower (higher) $t_{y}$ than otherwise for this 
particular reason, which is captured by the first term inside square brackets in the second row of equation (20b). By analogy, if $\alpha^{1}<\alpha^{2}$, the externality correcting part of $t_{x}$ would be too high for the low-ability type, in which case the government would like to use the tax on the clean good as an indirect instrument to increase the low-ability type's consumption of the dirty good. The second term inside square brackets in the second row of (20b) can be interpreted along similar lines. In other words, if the commodity tax on the dirty good is not a perfect instrument for internalizing the social cost of environmental damage, there is an incentive to modify the tax on the non-numeraire clean good by exploiting complementarity or substitutability between the clean and dirty goods. This is also interpretable to mean that Sandmo's additivity property no longer applies.

The inability of $t_{x}$ to fully internalize the externalities generated by the consumption of the dirty good will have implications also for the marginal income tax structure. By using the same approach as in Section 3, we can derive the following marginal income tax formulas:

$$
\begin{aligned}
& T_{I}^{1}=\frac{\lambda^{*}}{w^{1}}\left(M R S_{z, b}^{1}-\phi \widehat{M R S}_{z, b}^{2}\right)+\left(t_{x}-\alpha^{1} \frac{\mu}{\gamma}\right) \frac{1}{w^{1}} \frac{\partial \tilde{x}^{1}}{\partial z^{1}}+\frac{t_{y}}{w^{1}} \frac{\partial \tilde{y}^{1}}{\partial z^{1}} \\
& T_{I}^{2}=\left(t_{x}-\alpha^{2} \frac{\mu}{\gamma}\right) \frac{1}{w^{2}} \frac{\partial \tilde{x}^{2}}{\partial z^{2}}+\frac{t_{y}}{w^{2}} \frac{\partial \tilde{y}^{2}}{\partial z^{2}}
\end{aligned}
$$

where

$$
\begin{aligned}
& t_{x}-\alpha^{1} \frac{\mu}{\gamma}=\lambda^{*}\left(x^{1}-\hat{x}^{2}\right) \frac{\sum_{j} \partial \tilde{y}^{j} / \partial q_{y}}{\Omega}-\lambda^{*}\left(y^{1}-\hat{y}^{2}\right) \frac{\sum_{j} \partial \tilde{y}^{j} / \partial q_{x}}{\Omega}+\left(\alpha^{2}-\alpha^{1}\right) \theta^{2} \frac{\mu}{\gamma} \\
& t_{x}-\alpha^{2} \frac{\mu}{\gamma}=\lambda^{*}\left(x^{1}-\hat{x}^{2}\right) \frac{\sum_{j} \partial \tilde{y}^{j} / \partial q_{y}}{\Omega}-\lambda^{*}\left(y^{1}-\hat{y}^{2}\right) \frac{\sum_{j} \partial \tilde{y}^{j} / \partial q_{x}}{\Omega}+\left(\alpha^{1}-\alpha^{2}\right) \theta^{1} \frac{\mu}{\gamma}
\end{aligned}
$$

Compared to the benchmark model in Section 3 (where there are two motives for influencing the hours of work; to relax the self-selection constraint and to compensate the consumer for the distortions created by the commodity taxes), equations (21) and (22) imply a third motive for influencing the hours of work: externality correction. The reason behind this additional motive for marginal income taxation is that the tax on the dirty good is not a flexible enough instrument for internalizing the non-atmospheric externality. The intuition is similar to that behind the corrective parts of the tax on the non-numeraire clean good. 
To see this more clearly, consider first the marginal income tax rate implemented for the lowability type in equation (21a). If $\alpha^{1}>\alpha^{2}$, we know from above that the corrective part of $t_{x}$ falls short of the marginal social damage generated by the low-ability type's consumption of the dirty good. It follows that the second term on the right hand side of equation (21a) is negative (positive) if leisure is complementary with (substitutable for) the dirty good in the sense that $\partial \tilde{x}^{1} / \partial z^{1}>0(<0)$. By implementing this policy, the government is able to reduce the lowability type's consumption of the dirty good. The opposite incentive to increase the low-ability type's consumption of the dirty good would obviously arise if $\alpha^{1}<\alpha^{2}$. The interpretation of the marginal income tax rate facing the high-ability type is analogous.

\subsection{Border Trade}

Another case when the additivity property does not necessarily apply is when the dirty good can be purchased both at home and abroad. To briefly illustrate this case, let us return to the reference model presented in Section 3 with the modification that the dirty good can also be purchased abroad. ${ }^{25}$ If we let $x_{d}^{j}$ and $x_{a}^{j}$ denote the quantities of the dirty good that an individual of abilitytype $j$ buys domestically and abroad, respectively, the private (first-stage) budget constraint can be written as $b^{j}=c^{j}+q_{y} y^{j}+q_{x} x_{d}^{j}+\pi_{x} x_{a}^{j}+r\left(x_{a}^{j}\right)$, where $q_{x}=p_{x}+t_{x}$ denotes the domestic consumer price of the dirty good (as before), $\pi_{x}$ is the consumer price facing the agent if she purchases the dirty good abroad, and $r\left(x_{a}^{j}\right)$ is a transportation cost of importing the good. We assume that this cost is increasing and convex in $x_{a}^{j}$, and all interpretations below are based on the assumption that $\pi_{x}<q_{x}$. The private first-order condition for an optimal choice of $x_{a}^{j}$ is given by $q_{x}=\pi_{x}+r^{\prime}\left(x_{a}^{j}\right)$ which implies that $x_{a}^{j}$ becomes an increasing function of $q_{x}$. Finally, we assume that the dirty good, regardless of whether it is purchased at home or abroad, is consumed at home. This means that the externality is given by $E=\sum_{j} x^{j}$, where $x^{j}=x_{d}^{j}+x_{a}^{j}$.

The optimal income and commodity tax policy will depend on the possibility of influencing the dirty good purchased abroad via trade policy. If such options were available, the marginal income and commodity tax structure would take exactly the same form as in the benchmark model. However, if trade policy for some reason is not an available option (e.g., due to free trade

\footnotetext{
${ }^{25}$ The modelling approach in this part is based on Aronsson and Sjögren (2010).
} 
agreements), the policy incentives will resemble those of a non-atmospheric externality addressed in the previous subsection. We will focus on the latter case in what follows. The social decisionproblem thus takes the same form as in Section 3, with the exceptions that (i) the dirty good can be bought both at home and abroad, and (ii) the government lacks a direct instrument through which to affect the import of the dirty good. By using the same procedure as in Section 3, we end up with the following expressions for commodity taxation:

$$
\begin{aligned}
& t_{x}=\lambda^{*}\left(x^{1}-\hat{x}^{2}\right) \frac{\sum_{j} \partial \tilde{y}^{j} / \partial q_{y}}{\Omega_{d}}-\lambda^{*}\left(y^{1}-\hat{y}^{2}\right) \frac{\sum_{j} \partial \tilde{y}^{j} \partial q_{x}}{\Omega_{d}}+\frac{\mu}{\gamma}+\frac{\mu}{\gamma} \frac{\sum_{j} \partial x_{a}^{j} / \partial q_{x}}{\Omega_{d}} \sum_{j} \frac{\partial \tilde{y}^{j}}{\partial q_{y}} \\
& t_{y}=\lambda^{*}\left(y^{1}-\hat{y}^{2}\right) \frac{\sum_{j} \tilde{x}_{d}^{j} / \partial q_{x}}{\Omega_{d}}-\lambda^{*}\left(x^{1}-\hat{x}^{2}\right) \frac{\sum_{j} \partial \tilde{x}_{d}^{j} / \partial q_{y}}{\Omega_{d}}-\frac{\mu}{\gamma} \frac{\sum_{j} \partial x_{a}^{j} / \partial q_{x}}{\Omega_{d}} \sum_{j} \frac{\partial \tilde{x}_{d}^{j}}{\partial q_{y}}
\end{aligned}
$$

where $\Omega_{d}=\sum_{j} \frac{\partial \tilde{x}_{d}^{j}}{\partial q_{x}} \sum_{j} \frac{\partial \tilde{y}^{j}}{\partial q_{y}}-\sum_{j} \frac{\partial \tilde{x}_{d}^{j}}{\partial q_{y}} \sum_{j} \frac{\partial \tilde{y}^{j}}{\partial q_{x}}$. As before, all interpretations will be based on the assumption that $\Omega_{d}>0$.

The first three terms on the right hand side of (23a) are analogous to their counterparts in equation (14a), and the first two terms on the right hand side of (23b) are analogous to their counterparts in equation (14b), and will not be further discussed here. The novelty compared to the commodity tax formulas in the benchmark model (the equations in [14]) is the appearance of the final term on the right hand side of equations (23a) and (23b). First, note that $\partial x_{a}^{j} / \partial q_{x}>0$ and $\partial \tilde{y}^{j} / \partial q_{y}<0$, meaning that the final term on the right hand side of equation (23a) is negative. This has a strong implication: the corrective component of the dirty good tax - as given by the sum of the two final terms in equation (23a) - falls short of the social shadow price of the environmental damage, $\mu / \gamma$. The intuition is that the domestic tax base for the dirty good does not exactly correspond to the externality-generating consumption base, meaning that the tax is no longer a perfect instrument for correction. Note also that the more sensitive the level of border trade is to the domestic consumer price, i.e. the larger $\partial x_{a}^{j} / \partial q_{x}$, the smaller will be the corrective part of the commodity tax on the dirty good, ceteris paribus.

Second, and by analogy to the results in subsection 4.1, since the commodity tax on the dirty is no longer a perfect instrument for externality correction, the government has an incentive to use other instruments in order to influence the consumption of the dirty good. In the tax formula for 
the clean good, i.e., equation (23b), this aspect is captured by the final term on the right hand side. If the clean good is complementary with (substitutable for) the dirty good in the sense that $\partial \tilde{x}_{d}^{j} / \partial q_{y}<0(>0)$, then $t_{y}$ will be set at a higher (lower) level than otherwise. Externality correction thus constitutes a motive to tax complements to the dirty good and subsidize substitutes for the dirty good.

Third, the fact that $t_{x}$ is not a perfect instrument to control the total consumption of the dirty good also affects the policy incentives underlying marginal income taxation. By applying the same procedure as in Section 3, we can write the marginal income tax rates as follows:

$$
\begin{aligned}
& T_{I}^{1}=\frac{\lambda^{*}}{w^{1}}\left(M R S_{z, b}^{1}-\phi \widehat{M R S}_{z, b}^{2}\right)+\left(t_{x}-\frac{\mu}{\gamma}\right) \frac{1}{w^{1}} \frac{\partial \tilde{x}_{d}^{1}}{\partial z^{1}}+t_{y} \frac{1}{w^{1}} \frac{\partial \tilde{y}^{1}}{\partial z^{1}} \\
& T_{I}^{2}=\left(t_{x}-\frac{\mu}{\gamma}\right) \frac{1}{w^{2}} \frac{\partial \tilde{x}_{d}^{2}}{\partial z^{2}}+t_{y} \frac{1}{w^{2}} \frac{\partial \tilde{y}^{2}}{\partial z^{2}}
\end{aligned}
$$

Although equations (24a) and (24b) have the same form as the marginal income tax rates in Section 3 (equations [17a] and [17b]), an important difference in that $t_{x}-\mu / \gamma$ now depends explicitly on $\mu / \gamma$, and that the commodity tax on the non-numeraire clean good also depends explicitly on $\mu / \gamma$. This is easily seen by rewriting equation (23a) such that

$$
t_{x}-\frac{\mu}{\gamma}=\lambda^{*}\left(x^{1}-\hat{x}^{2}\right) \frac{\sum_{j} \partial \tilde{y}^{j} / \partial q_{y}}{\Omega_{d}}-\lambda^{*}\left(y^{1}-\hat{y}^{2}\right) \frac{\sum_{j} \partial \tilde{y}^{j} / \partial q_{x}}{\Omega_{d}}+\frac{\mu}{\gamma} \frac{\sum_{j} \partial x_{a}^{j} / \partial q_{x}}{\Omega_{d}} \sum_{j} \frac{\partial \tilde{y}^{j}}{\partial q_{y}}
$$

Since border trade induces the government to set the corrective part of $t_{x}$ below $\mu / \gamma$ for reasons explained above, there is a corrective motive for stimulating the hours of work for ability-type $j$ if leisure is complementary with the dirty $\operatorname{good}\left(\partial \tilde{x}_{d}^{j} / \partial z^{j}>0\right)$ and reduce the hours of work if leisure is substitutable for the dirty $\operatorname{good}\left(\partial \tilde{x}_{d}^{j} / \partial z^{j}<0\right)$. The interpretation of the term proportional to $t_{y}$ is analogous. The bottom line is that the policy rules for $t_{x}-\mu / \gamma$ and $t_{y}$ depend explicitly on the social shadow price of the externality, $\mu / \gamma$, implying that the efficient marginal income tax rates also depend on this shadow price.

\section{Transboundary Environmental Damage}

When the environmental problem is transboundary, national policies typically fail to fully internalize the associated externalities. The reason is that national policies are likely to reflect 
national objectives and constraints, which do not recognize the welfare costs that domestic agents impose on other countries. In this section, we extend the analysis to a framework with two countries, where the externality generated in each country spills over to the other country.

\subsection{Briefly on Cooperation in a Two-Country Benchmark}

Transboundary environmental externalities were integrated into a model of optimal mixed taxation by Aronsson and Blomquist (2003), in which a non-cooperative Nash equilibrium and cooperative equilibrium were compared from the perspective of optimal income and commodity taxation. ${ }^{26}$ Following Aronsson and Blomquist, it is easy to extend the benchmark model to a two country economy, where the preferences of the residents in each country take the same general form as in equation (1). We can then characterize the tax policy implicit in a Paretoefficient, cooperative equilibrium. To exemplify, let superscript $i$ be the country indicator, and let the environmental damage facing the residents in each country be given by the aggregate consumption of the dirty good measured over both countries, i.e., $E=\sum_{i}\left[x^{i, 1}+x^{i, 2}\right]$. Without any labor mobility between the countries, a globally efficient resource allocation can be derived by assuming that a (hypothetical) social planner maximizes the utility of the low-ability type in one of the countries, say, country 1 , subject to (i) a minimum utility constraint for the high-ability type in the same country, (ii) minimum utility restrictions for both ability-types in the other country, (iii) self-selection constraints for each country (each of which takes the same form as equation [9]), and (iv) an overall resource constraint. It is then straightforward to calculate a global-economy-analogue to equation (12) given as follows (based on the same notation as above):

$$
\frac{\mu}{\gamma}=\sigma \sum_{i}\left[\sum_{j} M W P_{E, b}^{i, j}+\lambda^{i, *}\left(M W P_{E, b}^{i, 1}-\widehat{M W P}_{E, b}^{i, 2}\right)-\sum_{j} t_{x}^{i} \frac{\partial \tilde{x}^{i, j}}{\partial E}-\sum_{j} t_{y}^{i} \frac{\partial \tilde{y}^{i, j}}{\partial E}\right]
$$

where

$$
\frac{1}{\sigma}=1-\sum_{i}\left[\frac{\partial \tilde{x}^{i, 1}}{\partial E}+\frac{\partial \tilde{x}^{i, 2}}{\partial E}\right]
$$

\footnotetext{
26 Aronsson and Johansson-Stenman (2015) address the implications of transboundary consumption externalities emanating from relative consumption concerns, and analyze the implications of such comparisons for optimal redistributive income taxation in a non-cooperative (Nash and Stackelberg) equilibrium and cooperative equilibrium, respectively.
} 
Equation (12a) means that the social marginal value of a cleaner environment (i.e., the social shadow price of the environmental damage) reflects the sum of the marginal willingness to pay to avoid the externality measured among the consumers in both countries, as well as the selfselection constraints and tax base effects in both countries. In other words, we just sum of country-specific components (as described in the benchmark model) to arrive at the correct social shadow price.

Conditional on $\mu / \gamma$ in equation (12a), the commodity taxes implemented in each country can still be characterized in the same general way as in equations (14) and the marginal income tax rates as in equations (17). Therefore, each tax instrument plays exactly the same role as in the benchmark model, with the only modification that the marginal social value of a cleaner environment is given by equation (12a) instead of equation (12). The intuition is, of course, that all interaction between the countries originates from the environmental externality in this example.

\subsection{A Model of Non-Cooperative Behavior}

Since global social planners do not exist (at least not to our knowledge), it is clearly useful to examine the policies that would follow from non-cooperative behavior. In studying tax policy by national governments, we follow the modelling approach of Aronsson, Persson, and Sjögren (2014) in considering two "large open economies", whose governments realize that their policy choices may significantly affect the world market producer price of the externality-generating good. This model provides a rich structure, where inefficiencies (due to cross-country interaction) arise both because the environmental externality that each country generates spills over to the other country, and because the countries may act strategically in trying to influence the environmental externalities via the producer price of the externality-generating good. ${ }^{27} \mathrm{~A}$ small open economy model follows as the special case where each country treats the world market producer price of the externality-generating good as exogenous. In addition, our model encompasses "emission leakage" in a natural way and integrates it into the theory of optimal

\footnotetext{
27 Other possible reasons why uncoordinated fiscal policies are inefficient (albeit not addressed here) include tax competition and fiscal externalities. See Cremer and Gahvari (2005) for some analysis in that direction.
} 
mixed taxation. ${ }^{28}$ Such leakage arises here because increased emission taxation in one of the countries reduces the demand for the externality-generating good and thus also reduces the producer price of this good, which tends to increase the emissions generated abroad.

We start by characterizing the income and commodity tax policy in a non-cooperative Nash equilibrium, where each national government treats the policy variables of the other country as exogenous, and end with a brief discussion of the welfare consequences of marginal policy coordination.

Consider a set-up with two countries, denoted $i=m, n$, which are large in the sense that each national government is able to affect the world market producer price of the externalitygenerating good. Except for the country indicator attached to some of the variables, the notations are the same as above. Without any loss of generality, we simplify by omitting the non-numeraire clean good $y$ throughout this section. To simplify the analysis of marginal policy coordination below, we also add the assumption that each individual has preferences for a public good, $G$, which enters each ability-type's utility function additively via the sub-utility function $\varphi\left(G^{i}\right)$; otherwise the ability-types have the same preferences as in the benchmark model in Sections 2 and 3. The utility function facing ability-type $j$ in country $i$ can then be written as

$$
u^{i, j}=u\left(c^{i, j}, x^{i j}, z^{, j j}, G^{i}, E\right)=\vartheta\left(c^{i, j}, x^{i j}, z^{, i j}, E\right)+\varphi\left(G^{i}\right) .
$$

There are two production sectors, denoted $c$ and $x$, respectively, which produce the two consumer goods (good $c$ and good $x$ ), and the goods can be traded between the two countries. The production functions can be written as $F_{c}^{i}\left(l_{c}^{i, 2}, l_{c}^{i, 1}\right)$ and $F_{x}^{i}\left(l_{x}^{i, 2}, l_{x}^{i, 1}\right)$, respectively, where $l_{c}^{i, j}$ and $l_{x}^{i, j}$ are the amounts of labor of type $j$ employed in sectors $c$ and $x$ in country $i$, such that $l_{c}^{i, j}+$ $l_{x}^{i, j}=l^{i, j}=1-z^{i, j}$ for $j=1,2$. It is assumed that both inputs are essential, that the marginal product of each input is positive and diminishing, and that the production technologies are characterized by constant returns to scale. Normalizing the production functions with respect to the hours of work supplied by the low-ability type in each sector, we obtain $f_{c}^{i}\left(n_{c}^{i}\right)=F_{c}^{i}(\cdot) / l_{c}^{i, 1}$

\footnotetext{
28 The leakage problem has been discussed many times in earlier literature, albeit in contexts different from ours; see e.g., Gurzgen and Rauscher 2000), Conconi (2003), and Lai and Hu (2005),
} 
and $f_{x}^{i}\left(n_{x}^{i}\right)=F_{x}^{i}(\cdot) / l_{x}^{i, 1}$ where $n_{c}^{i}=l_{c}^{i, 2} / l_{c}^{i, 1}$ and $n_{x}^{i}=l_{x}^{i, 2} / l_{x}^{i, 1}$. It is assumed that the workers are perfectly mobile between sectors but immobile between countries. This assumption simplifies the analysis and implies that the type-specific wage rates in country $i$ will be the same in both sectors. The necessary conditions for profit maximization can be written as follows:

$$
\begin{aligned}
w^{i, 2}=\frac{\partial f_{c}^{i}\left(n_{c}^{i}\right)}{\partial n_{c}^{i}}, & w^{i, 1}=f_{c}^{i}\left(n_{c}^{i}\right)-n_{c}^{i} \frac{\partial f_{c}^{i}\left(n_{c}^{i}\right)}{\partial n_{c}^{i}} \\
w^{i, 2}=p_{x} \frac{\partial f_{x}^{i}\left(n_{x}^{i}\right)}{\partial n_{x}^{i}}, & w^{i, 1}=p_{x} f_{x}^{i}\left(n_{x}^{i}\right)-p_{x} n_{x}^{i} \frac{\partial f_{x}^{i}\left(n_{x}^{i}\right)}{\partial n_{x}^{i}}
\end{aligned}
$$

where $p_{x}$ is the world market producer price of the dirty good. Combining the equations in (26a) and (26b) with the identities $l^{i, 2}=l_{c}^{i, 2}+l_{x}^{i, 2}$ and $l^{i, 1}=l_{c}^{i, 1}+l_{x}^{i, 1}$ allows us to define $w^{i, j}, l_{c}^{i, j}$ and $l_{x}^{i, j}$ (for $j=1,2$ ) as functions of $l^{i, 2}, l^{i, 1}$ and $p_{x}$. Substituting $l_{c}^{i, j}\left(l^{i, 1}, l^{i, 2}, p_{x}\right)$ and $l_{x}^{i, j}\left(l^{i, 1}, l^{i, 2}, p_{x}\right)$ into the production functions gives the equilibrium supply functions which we denote $S_{c}^{i}\left(l^{i, 1}, l^{i, 2}, p_{x}\right)$ and $S_{x}^{i}\left(l^{i, 1}, l^{i, 2}, p_{x}\right)$, respectively. Since the two consumption goods can be traded between the countries, equilibrium in the market for the dirty good satisfies ${ }^{29}$

$$
S_{x}^{m}+S_{x}^{n}-\sum_{j}\left(x^{m, j}+x^{n, j}\right)=0 .
$$

By using that $q_{x}^{i}=p_{x}+t_{x}^{i}$, equation (27) implicitly defines $p_{x}$ as a function of the two governments' decision variables $\left(b^{i, 1}, b^{i, 2}, l^{i, 1}, l^{i, 2}, t_{x}^{i}\right)$ for $i=m, n$, as well as a function of $E$. Finally, since the environmental damage is transboundary, it follows that $E=\sum_{j}\left(x^{m, j}+x^{n, j}\right)$.

The optimization problem facing the government in country $i$ is to maximize the utility of the low-ability type subject to (i) the given level of utility for the high-ability type, (ii) the selfselection constraint, (iii) the budget constraint, and (iv) the environmental constraint. Since $w^{i, 1}$ and $w^{i, 2}$ are both functions of $l^{i, 1}, l^{i, 2}$ and $p_{x}$, also the relative wage rate, $\phi^{i}=w^{i, 1} / w^{i, 2}$, becomes a function of these variables. The tax revenue is used to finance redistribution and the provision of the public good. Therefore, government $i$ 's budget constraint is given by $G^{i}=$ $\sum_{j}\left(w^{i, j} l^{i, j}-b^{i, j}+t_{x}^{i} x^{i, j}\right)$. By using the individual budget constraints and the zero profit conditions following from the assumption of constant returns to scale in the production, we can

${ }^{29}$ It follows from Walras' Law that the market for good $c$ is also in equilibrium. 
then rewrite this budget constraint to $\operatorname{read} G^{i}=S_{c}^{i}+p_{x} S_{x}^{i}+\sum_{j}\left(t_{x}^{i} x^{i, j}-b^{i, j}\right)$. Government $i=m, n$ treats $p_{x}$ as an endogenous variable and acts as a first mover via-a-vis the private agents in both countries but treats the policy variables chosen by the other government as exogenous.

By using $v^{i, j}$ to denote the indirect utility function of ability-type $j$ in country $i$, the Lagrangean associated with government $i$ 's maximization problem can be written as follows (the problem facing government $k \neq i$ is analogous)

$$
\begin{aligned}
L^{i} & =v^{i, 1}+\eta^{i}\left(v^{i, 2}-\bar{v}^{i, 2}\right)+\lambda^{i}\left(v^{i, 2}-\hat{v}^{i, 2}\right)+\mu^{i}\left[E-\sum_{j}\left(x^{i, j}+x^{k, j}\right)\right] \\
& +\gamma^{i}\left[S_{c}^{i}+p_{x} S_{x}^{i}+\sum_{j}\left(t_{x}^{i} x^{i, j}-b^{i, j}\right)-G^{i}\right] .
\end{aligned}
$$

The first-order conditions associated with government $i$ 's maximization problem are presented in the Appendix. A non-cooperative Nash-equilibrium is defined to imply that both countries satisfy all their first-order conditions (including the Lagrange constraints) simultaneously. We will here present the income and commodity tax structure implicit in Nash-equilibrium. Furthermore, since the public good was introduced in order to simplify the cost benefit analysis of marginal policy coordination to be discussed at the end of this subsection, we abstract from public good provision when characterizing the non-cooperative tax policies, i.e., $G^{i}=0$ to begin with.

Let us begin with the commodity tax on the dirty good. In the Appendix, we show that the commodity tax implemented by country $i$ takes the following form:

$$
t_{x}^{i}=\frac{\lambda^{i, *}}{\sum_{j} \partial \tilde{x}^{i, j} / \partial q_{x}^{i}}\left(x^{i, 1}-\hat{x}^{i, 2}\right)-\frac{\lambda^{i} l^{i, 1} \hat{v}_{z}^{i, 2}}{\beta^{i} \chi^{i} \gamma^{i}} \frac{\partial \phi^{i}}{\partial p_{x}}+\varphi^{i} \frac{\mu^{i}}{\gamma^{i}}-\frac{N X^{i}}{\beta^{i} \chi^{i}}
$$

where $N X^{i}=S_{x}^{i}-\sum_{j} x^{i, j}$ is country $i^{\prime}$ s net export of the dirty good, $\chi^{i}=1+\partial p_{x} / \partial t_{x}^{i}>0$, and where

$$
\beta^{i}=\sum_{i} \frac{\partial S_{x}^{i}}{\partial p_{x}}-\sum_{i} \sum_{j} \frac{\partial x^{i, j}}{\partial q_{x}^{i}}>0, \quad \varphi^{i}=\frac{\sum_{i} \frac{\partial S_{x}^{i}}{\partial p_{x}}}{\sum_{i} \frac{\partial S_{x}^{i}}{\partial p_{x}}-\sum_{j} \frac{\partial x^{k, j}}{\partial q_{x}^{i}}} \in(0,1)
$$

for $k \neq i$. The first term on the right hand side of equation (28) is analogous to the corresponding term in equation (14a). The second term is also a consequence of the self-selection constraint; 
albeit for another reason. It arises because a change in the producer price of the dirty good induced by an increase in the commodity tax - influences the relative wage rate. ${ }^{30}$ As a consequence, the relative wage rate provides yet another channels through which to relax the selfselection constraint. Since $\partial p_{x} / \partial t_{x}^{i}<0,{ }^{31}$ a higher (lower) commodity tax on the dirty good will relax the self-selection constraint if $\partial \phi^{i} / \partial p_{x}<0(>0)$, which provides an incentive to implement a higher (lower) $t_{x}^{i}$ than otherwise.

The incentive to correct for the externality is captured by the third term on the right hand side of equation (28), where $\mu^{i} / \gamma^{i}$ denotes the value that government $i$ attaches to a cleaner environment. This shadow price can be written as

$$
\begin{aligned}
\frac{\mu^{i}}{\gamma^{i}} & =\breve{\sigma}^{i}\left[\sum_{j} M W P_{E, b}^{i, j}+\lambda^{i, *}\left(M W P_{E, b}^{i, 1}-\widehat{M W P} P_{E, b}^{i, 2}\right)-\sum_{j} t_{x}^{i} \frac{\partial \tilde{x}^{i, j}}{\partial E}\right] \\
& +\frac{\breve{\sigma}^{i}\left(1-\sigma^{i}\right)}{\beta^{i} \chi}\left(\frac{\lambda^{i} l^{i, 1} \hat{v}_{z}^{i, 2}}{\gamma^{i}} \frac{\partial \phi^{i}}{\partial p_{x}}+N X^{i}\right)
\end{aligned}
$$

where

$$
\frac{1}{\sigma^{i}}=1-\sum_{j} \frac{\partial \tilde{x}^{i, j}}{\partial E}-\sum_{j} \frac{\partial x^{k, j}}{\partial E}, \quad \frac{1}{\bar{\sigma}^{i}}=\frac{1+\left(1-\sigma^{i}\right)\left[\sum_{j} \frac{\partial \tilde{x}^{k, j}}{\partial q_{x}^{k}}\right] / \beta^{i} \chi}{\sigma^{i}} .
$$

The first row of equation (29) is analogous to the expression for the shadow price in equation (12) above. The novelty here is the appearance of the second row, which is a consequence of the assumption that the world market producer price is endogenous. An increase in the environmental damage may thus influence the world market producer price which, in turn, affects the relative wage and the value of the net export of the dirty good. In general, this additional effect is ambiguous in sign and depends on (i) the relationship between the environmental damage and the producer price, $p_{x}$, (ii) the relationship between the producer price and the relative wage rate, and (iii) whether country $i$ is a net exporter or net importer of the externality-generating good. Since the specific details of these possible interactions are not important for the discussion given below, we refer the reader to Aronsson, Persson, and Sjögren (2014) for a more thorough interpretation.

\footnotetext{
${ }^{30}$ This mechanism would also appear in a one-country model, such as the benchmark model, if based on a more general technology. See Naito (1999).

${ }^{31}$ A higher commodity tax has a negative effect on the demand for the dirty good and, therefore, also on $p_{x}$.
} 
Returning to equation (28), an interesting aspect is that the effect of $\mu^{i} / \gamma^{i}$ is scaled down by the factor $\varphi^{i}<1$. Therefore, the externality-correcting component of the tax on the dirty good falls short of the marginal value the government attaches to a cleaner environment. This is a consequence of the assumption that each national government takes the leakage phenomenon described above into account. Although a lower domestic tax leads to more environmental damage generated in country $i$ (compared to a case where the domestic externality is fully internalized), it also leads to a decrease in the environmental damage generated in the other country, ceteris paribus. More specifically, by setting the externality-correcting part of the commodity tax below $\mu^{i} / \gamma^{i}$, the domestic demand for the dirty will be higher than under full domestic externality correction. In turn, this leads to a higher world market producer price, $p_{x}$, which reduces the demand for the dirty good in the other country. The latter contributes to reduce $E$ and is, therefore, welfare improving from the point of view of country $i^{32}$

The final term on the right hand side of equation (28) reflects a terms of trade effect. If country $i$ is a net exporter of the dirty good, then a higher producer price increases the value of the net export which, itself, is welfare improving. Since an increase in the domestic commodity tax leads to a lower world market producer price of the dirty good (i.e., $\partial p_{x} / \partial t_{x}^{i}<0$ ), the terms of trade effect motivates a lower commodity tax. Instead, if country $i$ is a net importer of the dirty good, the terms of trade effect correspondingly motivates a higher commodity tax.

Before characterizing the marginal income tax policy, it is useful to evaluate how an increase in $p_{x}$ affects the welfare in country $i$. By using that the national welfare function in country $i, W^{i}$, equals the national Lagrangean, $L^{i}$, in Nash-equilibrium, it can be shown (see the Appendix) that this welfare effect is given by

\footnotetext{
${ }^{32}$ In a small open economy, in which the producer price of the dirty good is treated as exogenous by each national government, it is straightforward to use the calculations presented in the Appendix to show that equation (28) reduces to read

$$
t_{x}^{i}=\frac{\lambda^{i, *}}{\sum_{j} \partial \tilde{x}^{i, j} / \partial q_{x}^{i}}\left(x^{i, 1}-\hat{x}^{i, 2}\right)+\frac{\mu^{i}}{\gamma^{i}}
$$

In a small open economy, the externality-correcting part of the tax on the dirty good coincides with the national government's perception of the marginal social value of a cleaner environment. Therefore, it is also straightforward to show that the additivity property will apply in the special case of a small open economy.
} 


$$
\frac{\partial W^{i}}{\partial p_{x}}=\frac{\gamma^{i}}{\chi^{i}}\left(\frac{\lambda^{i} l^{i, 1} \hat{v}_{z}^{i, 2}}{\gamma^{i}} \frac{\partial \phi^{i}}{\partial p_{x}}+N X^{i}-\frac{\mu^{i}}{\gamma^{i}} \sum_{j} \frac{\partial x^{k, j}}{\partial q_{x}^{k}}\right)
$$

where $\chi^{i}=1+\partial p_{x} / \partial t_{x}^{i}>0$. Equation (30) shows that an increase in $p_{x}$ affects welfare in country $i$ via three distinct channels. The first is a redistributive component which works through the self-selection constraint and arises because an increase in $p_{x}$ affects the relative wage rate, $\phi^{i}=w^{i, 1} / w^{i, 2}$. If $\partial \phi^{i} / \partial p_{x}>0$, it follows that the mimicker must supply more labor to reach the same before-tax income as the low-ability type, meaning that mimicking becomes less attractive. This contributes to relax the self-selection constraint which is welfare improving. By an analogous argument, the first term is negative if $\partial \phi^{i} / \partial p_{x}<0$. The second channel through which an increase in $p_{x}$ influences welfare in country $i$ goes via a terms of trade effect, the sign of which depends on whether the country is a net exporter $\left(N X^{i}>0\right)$ or net importer $\left(N X^{i}<0\right)$ of the dirty good. Finally, an increase in $p_{x}$ contributes to reduce the demand for the dirty good in the other country. All else equal, this reduces the environmental damage, which improves the welfare in country $i$.

The marginal labor income taxes implemented by the government in country $i$ can be written as follows:

$$
\begin{aligned}
T_{I}^{i, 1} & =\frac{\lambda^{i, *}}{w^{i, 1}}\left(M R S_{z, b}^{i, 1}-\phi^{i} \widehat{M R S_{z, b}^{i, 2}}\right)-\frac{\lambda^{i, *} l^{i, 1}}{w^{i, 1}} \widehat{M R S} S_{z, b}^{i, 2} \frac{\partial \phi^{i}}{\partial l^{i, 1}}+\left(t_{x}^{i}-\frac{\mu^{i}}{\gamma^{i}}\right) \frac{1}{w^{i, 1}} \frac{\partial \tilde{x}^{i, 1}}{\partial z^{i, 1}}-\frac{\Psi^{i, 1}}{w^{i, 1} \gamma^{i}} \frac{\partial W^{i}}{\partial p_{x}} \\
T_{I}^{i, 2} & =\frac{\lambda^{i, *} l^{i, 2}}{w^{i, 2}} \widehat{M R S_{z, b}^{i, 2}} \frac{\partial \phi^{i}}{\partial l^{i, 2}}+\left(t_{x}^{i}-\frac{\mu^{i}}{\gamma^{i}}\right) \frac{1}{w^{i, 2}} \frac{\partial \tilde{x}^{i, 2}}{\partial z^{i, 2}}-\frac{\Psi^{i, 2}}{w^{i, 2} \gamma^{i}} \frac{\partial W^{i}}{\partial p_{x}}
\end{aligned}
$$

where $\Psi^{i, j}=-\left(\partial S_{x}^{i} / \partial l^{i, 1}+\partial \tilde{x}^{i, 1} / \partial z^{i, 1}\right) / \beta^{i}$.

The first three terms on the right hand side of equation (31a) and the first two terms on the right hand side of equation (31b) are analogous to their counterparts in the benchmark model and interpretable is the same general way. The novelty here is the appearance of the final term in each equation, which captures the joint effect of two mechanisms: (i) how the world market producer price of the dirty good changes in response to an increase in the hours of work (captured by $\Psi^{i, j}$ ), and (ii) how an increase in $p_{x}$ affects the domestic welfare (given in equation [30]). For instance, if $p_{x}$ decreases in response to an increase in the hours of work supplied domestically such that $\Psi^{i, j}<0$ and if $\partial W^{i} / \partial p_{x}>0$, a policy-induced decrease in the labor supply would lead to a 
higher world market producer price of the dirty good and in the end also to higher domestic welfare, which gives an incentive for government $i$ to implement a higher marginal income tax rate for ability type $j$ than it would otherwise have done. Analogous policy incentives will follow if $\Psi^{i, j}>0$ and/or $\partial W^{i} / \partial p_{x}<0$.

From an environmental policy perspective, an interesting result is that the variables $t^{i}-\mu^{i} / \gamma^{i}$ and $\partial W^{i} / \partial p_{x}$, respectively, on the right hand side of equations (31a) and (31b) directly depend on the value that government $i$ attaches to a cleaner environment, i.e., $\mu^{i} / \gamma^{i}$. This is interpretable to mean that the income tax is used as an indirect instrument for externality-correction. The intuition is that each national government counteracts the environmental damage via two channels by (1) reducing the domestic consumption of the dirty good, and (2) trying to achieve a reduction of the dirty good consumption in the other country through a tax-induced increase in the world market price of the dirty good. The commodity tax on the dirty good is not a flexible enough instrument to target both these channels of influence, implying that the income tax will serve as a supplemental instrument for correction. As such, the additivity property is not applicable here.

The non-cooperative Nash equilibrium described in this subsection is inefficient for two reasons: first, the cross-border spillover effects of the environmental damage are uninternalized when the national governments behave as Nash-competitors to one another and, second, the countries act strategically by trying to influence each other's environmental damage through the (common) price of the externality-generating good. ${ }^{33}$ To take the discussion a bit further, let us consider marginal policy coordination where the two governments agree upon smaller projects with the stated purpose of improving the total welfare, and where the non-cooperative Nash equilibrium constitutes the reference point. To evaluate the welfare effects of this policy reform, we can utilize that the tax policy is optimally chosen on a national basis in the non-cooperative Nash equilibrium. Therefore, a coordinated infinitesimal change in one or several policy instruments only affects welfare because changes in the public decision variables in country $i$ give rise to welfare effects in country $k$, and vice versa. To illustrate, we consider a coordinated increase in

\footnotetext{
${ }^{33}$ The latter is a consequence of the assumption that the national governments can significantly affect the world market producer price; it would vanish in a framework with small open economies, which are price takers on the world market.
} 
the commodity tax where the increased tax revenue is balanced by a corresponding increase in the provision of the public good. A straightforward application of the Envelope Theorem gives the following welfare change for country $i$ (the welfare change facing country $k$ is analogous):

$$
d W^{i}=\left(-\mu^{i} \sum_{j} \frac{\partial x^{k, j}}{\partial q_{x}^{k}}+\frac{\partial W^{i}}{\partial p_{x}} \frac{\partial p_{x}}{\partial t_{x}^{k}}\right) d t_{x}^{k}
$$

Equation (32) shows that the policy reform influences the welfare in country $i$ through a direct effect on the foreign demand for the dirty good (which is positive since a marginal increase in $t_{x}^{k}$ reduces the environmental damage generated in the other country $k$ ), and an indirect effect via the world market producer price. If $\partial W^{i} / \partial p_{x}<0$, and since $\partial p_{x} / \partial t_{x}^{k}<0$, it follows from equation (32) that this policy coordination would unambiguously increase the welfare in country $i$. Since an analogous cost-benefit rule applies to country $k$, a similar conclusion also applies to the other country if $\partial W^{k} / \partial p_{x}<0$. Similar cost-benefit rules can be defined for policy coordination in terms of other instruments.

\section{An Overlapping Generations Economy with a Stock-Externality}

Many (if not most) environmental problems are intertemporal in nature, such that the environmental damage is generated by an accumulated stock (instead of a flow). The climate problem is the prime example; however, it is easy to think of other relevant examples as well. In this section, we extend the analysis to an overlapping generations (OLG) model with stockpollution, while still retaining essential features of the benchmark model examined in Sections 2 and 3. Earlier literature on optimal income taxation in OLG economies typically focuses on issues other than environmental externalities. ${ }^{34}$ Aronsson and Johansson-Stenman (2010) used an OLG model to analyze optimal redistributive income taxation in a model with consumption externalities generated by relative consumption concerns. The model set out below is similar to their framework; yet with the important modifications that (i) the consumption externality is a state-variable, and (ii) the government solves a mixed tax problem (instead of an optimal income tax problem).

\footnotetext{
${ }^{34}$ An important issue in earlier studies refers to the role of capital income taxation when the labor income tax is optimal. See the seminal contribution by Ordover and Phelps (1979) and the subsequent extensions by Brett (1997) and Pirttilä and Tuomala (2001).
} 


\section{Private Sector}

We assume that each individual lives for two periods; works in the first and is retired in the second. An individual entering the economy in period $t$ (who is young in period $t$ and old in period $t+1$ ) will be referred to as belonging to generation $t$ in what follows. The population is constant and the number of individuals of each ability-type and generation is normalized to one. The life-time utility function of an individual of ability-type $j$ and generation $t$ is written as follows:

$$
U_{t}^{j}=u\left(c_{1 t}^{j}, x_{1 t}^{j}, y_{1 t}^{j}, z_{1 t}^{j}, E_{t}\right)+\beta u\left(c_{2 t+1}^{j}, x_{2 t+1}^{j}, y_{2 t+1}^{j}, 1, E_{t+1}\right)
$$

where $\beta$ denotes the utility discount factor, and $E_{t}$ denotes the stock of pollution - our measure of environmental damage - in period $t$ (to be defined below). Since the individual does not work in the second period, leisure time coincides with the time endowment, normalized to unity. As a notational convention to be used throughout this section, sub-script " $1 t$ " refers to decisionvariables when the consumer is young in period $t$ and sub-script " $2 t+1$ " to decision variables when the consumer is old in period $t+1$.

The life-time budget constraint facing a consumer of ability-type $j$ and generation $t$ can then be written as

$$
\begin{aligned}
& w_{1 t}^{j} l_{1 t}^{j}-T_{t}\left(w_{1 t}^{j} l_{1 t}^{j}\right)-s_{1 t}^{j}=c_{1 t}^{j}+q_{x, t} x_{1 t}^{j}+q_{y, t} y_{1 t}^{j}+s_{1 t}^{j} \\
& \left(1+r_{t+1}\right) s_{1 t}^{j}-\Phi_{t+1}\left(r_{t+1} s_{1 t}^{j}\right)=c_{2 t+1}^{j}+q_{x, t+1} x_{2 t+1}^{j}+q_{y, t+1} y_{2 t+1}^{j}
\end{aligned}
$$

where $s_{1 t}^{j}$ denotes saving by the young ability type $j$ of generation $t, r_{t+1}$ denotes the interest rate in period $t+1$, and $\Phi_{t+1}\left(r_{t+1} s_{1 t}^{j}\right)$ denotes the capital income tax (positive or negative) paid by the same consumer when old. The remaining notation is the same as in the benchmark model except for the time and age indicators attached to the consumption variables, and that $\tau_{x, t}$ and $\tau_{y, t}$ are now used to denote the commodity taxes on the dirty good and clean non-numeraire good, respectively, in any period $t .{ }^{35}$ Both the labor income tax and the capital income tax are general, nonlinear functions. An individual of ability-type $j$ chooses $l_{1 t}^{j}, c_{1 t}^{j}, x_{1 t}^{j}, y_{1 t}^{j}, c_{2 t+1}^{j}, x_{2 t+1}^{j}$, and $y_{2 t+1}^{j}$ to maximize the utility function given in equation (33) subject to the budget constraint in

\footnotetext{
${ }^{35}$ This change of notation is motivated by the fact that $t$ is used as a time indicator here.
} 
equations (34). In doing so, each individual treats the before-tax wage rate, the interest rate, the consumer prices, and the environmental externality as exogenous.

As in the benchmark model, we solve the consumer's maximization problem in two stages. The reason is again that the conditional demand functions and conditional indirect utility functions are useful in the formulation of the optimal tax problem. In the first stage, we choose $c_{1 t}^{j}, x_{1 t}^{j}, y_{1 t}^{j}, c_{2 t+1}^{j}, x_{2 t+1}^{j}$ and $y_{2 t+1}^{j}$ to maximize utility subject to the following budget constraint:

$$
\begin{aligned}
& b_{1 t}^{j}=c_{1 t}^{j}+q_{x, t} x_{1 t}^{j}+q_{y, t} y_{1 t}^{j} \\
& b_{2 t+1}^{j}=c_{2 t+1}^{j}+q_{x, t+1} x_{2 t+1}^{j}+q_{y, t+1} y_{2 t+1}^{j}
\end{aligned}
$$

where $b_{1 t}^{j}$ is the available consumption space when young in period $t$ (i.e., the after-tax income net of saving) and $b_{2 t+1}^{j}$ is the available consumption space when old in period $t+1$ (saving plus the capital income net of tax). This gives the following conditional demand functions for the young ability-type $j$ :

$$
\zeta_{1 t}^{j}=\zeta\left(b_{1 t}^{j}, q_{x, t}, q_{y, t}, z_{1 t}^{j}, E_{t}\right) \text { for } \zeta=c, x, y
$$

and the following conditional demand functions for the old ability-type $j$ :

$$
\xi_{2 t+1}^{j}=\xi\left(b_{2 t+1}^{j}, q_{x, t+1}, q_{y, t+1}, E_{t+1}\right) \text { for } \xi=c, x, y
$$

The conditional indirect utility function is derived by substituting equations (36a) and (36b) into equation (33)

$$
V_{t}^{j}=v\left(b_{1 t}^{j}, q_{x, t}, q_{y, t}, z_{1 t}^{j}, E_{t}\right)+\beta v\left(b_{2 t+1}^{j}, q_{x, t+1}, q_{y, t+1}, E_{t+1}\right) .
$$

In the second stage, we choose the hours of work and savings to maximize the conditional indirect utility function subject to the budget constraints $b_{1 t}^{j}=w_{1 t}^{j} l_{1 t}^{j}-T_{t}\left(w_{1 t}^{j} l_{1 t}^{j}\right)-s_{1 t}^{j}$ and $b_{2 t+1}^{j}=\left(1+r_{t+1}\right) s_{1 t}^{j}-\Phi_{t+1}\left(r_{t+1} s_{1 t}^{j}\right)$. By using $d T_{t}^{j} / d I_{1 t}^{j}$ and $d \Phi_{t+1}^{j} / d I_{2 t+1}^{j}$ to denote the marginal labor income tax rate and marginal capital income tax rate, respectively, the first-order conditions for $l_{1 t}^{j}$ and $s_{1 t}^{j}$ can be written as 


$$
M R S_{z, b}^{j, t}=\left(1-\frac{d T_{t}^{j}}{d I_{1 t}^{j}}\right) w_{1 t}^{j}, \quad M R S_{b_{1}, b_{2}}^{j, t}=1+\left(1-\frac{d \Phi_{t+1}^{j}}{d I_{2 t+1}^{j}}\right) r_{t+1}
$$

where $I_{1 t}^{j}=w_{1 t}^{j} l_{1 t}^{j}, I_{2 t+1}^{j}=r_{t+1} s_{1 t}^{j}$, and where the two marginal rates of substitution are defined as

$$
M R S_{z, b}^{j, t}=\frac{\partial v_{1 t}^{j} / \partial z_{1 t}^{j}}{\partial v_{1 t}^{j} / \partial b_{1 t}^{j}}, \quad \quad M R S_{b_{1}, b_{2}}^{j, t}=\frac{\partial v_{1 t}^{j} / \partial b_{1 t}^{j}}{\beta \partial v_{2 t+1}^{j} / \partial b_{2 t+1}^{j}}
$$

To keep the model as simple as possible, we consider a closed economy with a linear production technology. The latter implies that the factor prices are fixed in each time period, although possibly varying between time periods (i.e., the linear production technology may change over time). The closed economy assumption implies that that the aggregate saving in period $t-1$ will constitute the aggregate capital stock in period $t$, i.e. $K_{t}=\sum_{j} s_{1 t-1}^{j}$.

Finally, we assume that the stock of pollution in any period $t, E_{t}$, equals the previous period's stock of pollution net of depreciation plus the release of emission in period $t$, which is given by the aggregate consumption of the dirty good, i.e.,

$$
E_{t}=(1-\rho) E_{t-1}+\sum_{j}\left(x_{1 t}^{j}+x_{2 t}^{j}\right)
$$

where $\rho$ denotes the rate of depreciation. Since the instantaneous contribution to the stock of pollution depends on the aggregate consumption of the dirty good, we can think of the externality implied by equation (39) as a dynamic analogue to the atmospheric externality in the benchmark model in Sections 2 and 3.

\section{Optimal Taxation}

We follow earlier literature on optimal redistributive taxation in OLG models (see, e.g., Pirttilä and Tuomala 2001; Aronsson and Johansson-Stenman 2010) in assuming that the government aims to maximize a general social welfare function $W\left(\sum_{j} V_{t}^{j}, \sum_{j} V_{t+1}^{j}, ..\right){ }^{36}$ Since there are two low-ability individuals and two high-ability individuals alive in each period (one young and one

\footnotetext{
${ }^{36}$ Since the resulting social optimum is Pareto efficient, the same policy rules for commodity taxation and marginal income taxation as those derived below would follow if we instead assume that the government aims to maximize the utility for one specific ability-type and generation subject to minimum utility restrictions for all other agents. This means that the results derived below are comparable to those presented above.
} 
old agent of each ability type), and if we assume public budget balance in each period to simplify the analysis, the public budget constraint in period $t$ is given by

$$
\sum_{j}\left[T_{t}\left(w_{1 t}^{j} l_{1 t}^{j}\right)+\Phi_{t}\left(r_{t} s_{1 t-1}^{j}\right)\right]+\tau_{x, t} \sum_{j}\left(x_{1 t}^{j}+x_{2 t}^{j}\right)+\tau_{y, t} \sum_{j}\left(y_{1 t}^{j}+y_{2 t}^{j}\right)=0
$$

By using the private budget constraints together with $K_{t}=\sum_{j} s_{1 t-1}^{j}$, we can rewrite equation (40) to read

$$
\sum_{j}\left(w_{1 t}^{j} l_{1 t}^{j}-b_{1 t}^{j}-b_{2 t}^{j}\right)+K_{t}\left(1+r_{t}\right)-K_{t+1}+\tau_{x, t} \sum_{j}\left(x_{1 t}^{j}+x_{2 t}^{j}\right)+\tau_{y, t} \sum_{j}\left(y_{1 t}^{j}+y_{2 t}^{j}\right)=0 .
$$

where the initial capital stock, $K_{0}$, is exogenously given. We assume - as we did in Sections 3, 4, and 5 - that innate ability is private information and that the government wants to redistribute from the high-ability to the low-ability type, which is termed the "normal case" by Stiglitz (1982). We must, therefore, impose a self-selection constraint such that each high-ability individual prefers the allocation intended for his/her type over the allocation intended for the lowability type. By using the life-time indirect utility function defined above, the self-selection constraint is written as follows:

$$
V_{t}^{2} \geq \widehat{V}_{t}^{2}=\underbrace{v\left(b_{1 t}^{1}, q_{x, t}, q_{y, t}, \hat{z}^{2}, E_{t}\right)}_{\hat{v}_{1 t}^{2}}+\beta \underbrace{v\left(b_{2 t+1}^{1}, q_{x, t+1}, q_{y, t+1}, E_{t+1}\right)}_{\hat{v}_{2 t+1}^{2}=v_{2 t+1}^{1}}
$$

where $\hat{z}_{1 t}^{2}=1-\phi l_{1 t}^{1}$ denotes the leisure time enjoyed by the mimicker.

Finally, the government recognizes that the stock of pollution accumulates according to equation (39), where the initial stock, $E_{0}$, is treated as exogenous. The social decision-problem is to choose $l_{1 t}^{1}, b_{1 t}^{1}, b_{2 t}^{1}, l_{1 t}^{2}, b_{1 t}^{2}, b_{2 t}^{2}, \tau_{x, t}, \tau_{y, t}, K_{t}$, and $E_{t}$ for all $t$ to maximize the social welfare function subject to equations (39), (41), and (42). The Lagrangean corresponding to this maximization problem can be written as follows in period zero: ${ }^{37}$

$$
\begin{aligned}
L_{0} & =W\left(V_{0}, V_{1}, . .\right)+\sum_{t=0}^{\infty} \lambda_{t}\left(V_{t}^{2}-\widehat{V}_{t}^{2}\right)+\sum_{t=0}^{\infty} \mu_{t}\left[E_{t}-(1-\rho) E_{t-1}-\sum_{j}\left(x_{1 t}^{j}+x_{21}^{j}\right)\right] \\
& +\sum_{t} \gamma_{t}\left[\sum_{j} w_{1 t}^{j} l_{1 t}^{j}+K_{t}\left(1+r_{t}\right)-K_{t+1}-\sum_{j}\left(b_{1 t}^{j}+b_{2 t}^{j}\right)\right]
\end{aligned}
$$

\footnotetext{
${ }^{37}$ To avoid any technical complications which do not add substance to the problem at hand, we make the simplifying assumption that there is no previous old generation alive in period zero.
} 


$$
+\sum_{t} \gamma_{t}\left[\tau_{x, t} \sum_{j}\left(x_{1 t}^{j}+x_{2 t}^{j}\right)+\tau_{y, t} \sum_{j}\left(y_{1 t}^{j}+y_{2 t}^{j}\right)\right]
$$

where $\lambda_{t}, \mu_{t}$ and $\gamma_{t}$ are the Lagrange multipliers (or, equivalently, the current value shadow prices) associated with the self-selection constraint, the stock of pollution and the resource constraint, respectively. The first-order conditions are presented in the Appendix.

A potential drawback with this formulation is that it may give rise to a time-inconsistency problem. The reason is that when the government at time zero determines its policy for any generation $t$, the planned choices of capital income taxation in period $t+1$, as well as the choices of $\tau_{x, t+1}$ and $\tau_{y, t+1}$ will be influenced by the self-selection constraint imposed on generation $t$ (if the self-selection constraint is binding). However, when period $t+1$ arrives, the individuals of generation $t$ have already revealed their true ability (which they do at the end of the first period of life if faced by proper type-revealing incentives). Furthermore, the individuals of generation $t$ are retired in period $t+1$, and mimicking is no longer an issue for that generation. Both these arguments imply that when period $t+1$ is reached, the government may want to revise the planned capital income tax policy for generation $t$, as well as the choices of $\tau_{x, t+1}$ and $\tau_{y, t+1}$. Therefore, a key question is whether the government at time zero can commit to a given policy plan. In the present paper, we follow the bulk of earlier comparable literature in assuming that the government can commit to the planned tax policy. Yet, we also realize that this assumption is questionable. $^{38}$

As in the benchmark model, the optimal tax policy will depend on the shadow price of the externality; in this case, the social value of a decrease in the stock of pollution. In the Appendix, we show that this shadow price takes the following form at any time $t$ :

$$
\begin{aligned}
\frac{\mu_{t}}{\gamma_{t}} & =\sum_{n=0}^{\infty} \frac{(1-\rho)^{n} \prod_{i=0}^{n} \sigma_{t+i}}{\prod_{i=1}^{n}\left(1+r_{t+i}\right)} \sum_{j}\left(M W P_{1 t+n}^{j}+M W P_{2 t+n}^{j}\right) \\
& +\sum_{n=0}^{\infty} \frac{(1-\rho)^{n} \prod_{i=0}^{n} \sigma_{t+i}}{\prod_{i=1}^{n}\left(1+r_{t+i}\right)}\left[\lambda_{t+n}^{*}\left(M W P_{1 t+n}^{1}-\widehat{M W P_{1 t+n}^{2}}\right)\right] \\
& -\sum_{n=0}^{\infty} \frac{(1-\rho)^{n} \prod_{i=0}^{n} \sigma_{t+i}}{\prod_{i=1}^{n}\left(1+r_{t+i}\right)}\left[\tau_{x, t+n} \sum_{j}\left(\frac{\partial \tilde{x}_{1 t+n}^{j}}{\partial E_{t+n}}+\frac{\partial \tilde{x}_{2 t+n}^{j}}{\partial E_{t+n}}\right)+\tau_{y, t+n} \sum_{j}\left(\frac{\partial \tilde{y}_{1 t+n}^{j}}{\partial E_{t+n}}+\frac{\partial \tilde{y}_{2 t+n}^{j}}{\partial E_{t+n}}\right)\right]
\end{aligned}
$$

\footnotetext{
${ }^{38}$ See, e.g., Brett and Weymark (2008), Gou and Krause (2015), and Aronsson and Sjögren (2016) for recent research on optimal nonlinear or mixed taxation without commitment.
} 
where we have used

$$
\begin{aligned}
& \lambda_{t+n}^{*}=\frac{\lambda_{t+n}}{\gamma_{t+n}} \frac{\partial \hat{v}_{1 t+n}^{2}}{\partial b_{1 t+n}^{1}}, \quad M W P_{1 t+n}^{j}=-\frac{\partial v_{1 t+n}^{j} / \partial E_{t+n}}{\partial v_{1 t+n}^{j} / \partial b_{1 t+n}^{j}}, \quad \widehat{M W P_{1 t+n}^{2}}=-\frac{\partial \hat{v}_{1 t+n}^{2} / \partial E_{t+n}}{\partial \hat{v}_{1 t+n}^{2} / \partial b_{1 t+n}^{1}} \\
& \frac{1}{\sigma_{t+i}}=1-\frac{\partial \tilde{x}_{1 t+i}^{1}}{\partial E_{t+i}}-\frac{\partial \tilde{x}_{1 t+i}^{2}}{\partial E_{t+i}}-\frac{\partial \tilde{x}_{2 t+i}^{1}}{\partial E_{t+i}}-\frac{\partial \tilde{x}_{2 t+i}^{2}}{\partial E_{t+i}} .
\end{aligned}
$$

Equation (44) is interpretable as an intertemporal analogue to equation (12). The first row reflects the present value of all future generations' marginal willingness to pay to avoid pollution, while the second row captures the difference between the young low-ability type's and the young mimicker's marginal willingness to pay to avoid pollution measured for all future generations. ${ }^{39}$ By analogy, the tax base effects are also measured for all future periods, which can be seen from the third row. The intuition behind the forward looking shadow price is that an increase in the flow-emissions in any period $t$, through an increase in the aggregate consumption of the dirty good, leads to a permanent increase in the stock of pollution (although the effect decreases over time due to depreciation). In other words, the release of emissions by the current generation reduces the well-being of all future generation, as well as influences the incentives faced by highability individuals to engage in mimicking in the future. Therefore, although equation (44) bears a close resemblance to equation (12) from a technical point of view, the two equations differ in a non-trivial way.

Given the social shadow price of the stock of pollution in equation (44), the policy rules for commodity taxation and marginal labor income taxation are analogous to equations (14) and (17), respectively, in the benchmark model. To exemplify, we show in the Appendix that the commodity tax on the dirty good and clean non-numeraire good, respectively, can be written as follows in any period $t$ :

$$
\tau_{x, t}=\lambda_{t}^{*}\left(x_{1 t}^{1}-\hat{x}_{1 t}^{2}\right) \frac{\sum_{j}\left(\frac{\partial \widetilde{y}_{1 t}^{j}}{\partial q_{y, t}}+\frac{\partial \widetilde{y}_{2 t}^{j}}{\partial q_{y, t}}\right)}{\Omega_{t}}-\lambda_{t}^{*}\left(y_{1 t}^{1}-\hat{y}_{1 t}^{2}\right) \frac{\sum_{j}\left(\frac{\partial \widetilde{y}_{1 t}^{j}}{\partial q_{x, t}}+\frac{\partial \widetilde{y}_{2 t}^{j}}{\partial q_{x, t}}\right)}{\Omega_{t}}+\frac{\mu_{t}}{\gamma_{t}}
$$

\footnotetext{
39 Note that equation (44) contains no corresponding difference between the old low-ability type's and the old mimicker's marginal willingness to pay to avoid pollution. The reason is that the common-for-all utility function given in equation (33) is intertemporally separable, and that each consumer is retired in the second period. Therefore, the old low-ability type and the old mimicker neither differ in terms of their marginal willingness to pay to avoid pollution (i.e., $M W P_{2 t+n}^{1}=\widehat{M W P}_{2 t+n}^{2}$ for all $n$ ) nor in terms of their consumption behavior.
} 


$$
\tau_{y, t}=\lambda_{t}^{*}\left(y_{1 t}^{1}-\hat{y}_{1 t}^{2}\right) \frac{\sum_{j}\left(\frac{\partial \widetilde{x}_{1 t}^{j}}{\partial q_{x, t}}+\frac{\partial \widetilde{x}_{2 t}^{j}}{\partial q_{x, t}}\right)}{\Omega_{t}}-\lambda_{t}^{*}\left(x_{1 t}^{1}-\hat{x}_{1 t}^{2}\right) \frac{\sum_{j}\left(\frac{\partial \widetilde{x}_{1 t}^{j}}{\partial q_{y, t}}+\frac{\partial \widetilde{x}_{2 t}^{j}}{\partial q_{y, t}}\right)}{\Omega_{t}}
$$

where

$$
\Omega_{t}=\sum_{j}\left(\frac{\partial \tilde{x}_{1 t}^{j}}{\partial q_{x, t}}+\frac{\partial \tilde{x}_{2 t}^{j}}{\partial q_{x, t}}\right) \sum_{j}\left(\frac{\partial \tilde{y}_{1 t}^{j}}{\partial q_{y, t}}+\frac{\partial \tilde{y}_{2 t}^{j}}{\partial q_{y, t}}\right)-\sum_{j}\left(\frac{\partial \tilde{y}_{1 t}^{j}}{\partial q_{x, t}}+\frac{\partial \tilde{y}_{2 t}^{j}}{\partial q_{x, t}}\right) \sum_{j}\left(\frac{\partial \tilde{x}_{1 t}^{j}}{\partial q_{y, t}}+\frac{\partial \tilde{x}_{2 t}^{j}}{\partial q_{y, t}}\right)
$$

Equations (45a) and (45b) take the same general form, and have the same interpretation, as their counterparts in the static benchmark model, i.e., equations (14a) and (14b). In particular, note that the social shadow price of the stock of pollution enters additively in the tax policy rule for the dirty good, while it has no direct effect in the tax policy rule for the clean non-numeraire good. The only differences are that (i) the taxes are period specific here, and (ii) the corrective component of the tax on the dirty good is forward looking. Whereas the former modification is just a consequence of the multi-period framework (in which commodity taxes are implemented in every period), the latter modification is clearly substantial as it adds an intertemporal dimension to the externality as well as to the corrective policy.

Since the marginal labor income taxes take the same form as in the benchmark model (see equations [17a] and [17b]), we refrain from characterizing the marginal labor income tax policy here. Let us, instead, turn to the marginal capital income tax structure. We show in the Appendix that the marginal capital income tax rates implemented for generation $t$ can be characterized as follows:

$$
\begin{aligned}
& \frac{d \Phi_{1 t+1}^{1}}{d I_{1 t+1}^{1}}=\frac{1+r_{t+1}}{r_{t+1}} \frac{\lambda_{t} \beta\left(\partial \hat{v}_{2 t+1}^{2} / \partial b_{2 t+1}^{1}\right)}{\gamma_{t}}\left(M R S_{b_{1}, b_{2}}^{1, t}-\widehat{M R S}_{b_{1}, b_{2}}^{2, t}\right) \\
& +\frac{1+r_{t+1}}{r_{t+1}}\left[\left(\tau_{x, t}-\frac{\mu_{t}}{\gamma_{t}}\right) \frac{\partial x_{1 t}^{1}}{\partial b_{1 t}^{1}}+\tau_{y, t} \frac{\partial y_{1 t}^{1}}{\partial b_{1 t}^{1}}\right]-\frac{M R S_{b_{1}, b_{2}}^{1, t}}{r_{t+1}}\left[\left(\tau_{x, t+1}-\frac{\mu_{t+1}}{\gamma_{t+1}}\right) \frac{\partial x_{2 t+1}^{1}}{\partial b_{2 t+1}^{1}}+\tau_{y, t+1} \frac{\partial y_{2 t+1}^{1}}{\partial b_{2 t+1}^{1}}\right] \text { (46a) } \\
& \frac{d \Phi_{1 t+1}^{2}}{d I_{1 t+1}^{2}}=\frac{1+r_{t+1}}{r_{t+1}}\left[\left(\tau_{x, t}-\frac{\mu_{t}}{\gamma_{t}}\right) \frac{\partial x_{1 t}^{2}}{\partial b_{1 t}^{2}}+\tau_{y, t} \frac{\partial y_{1 t}^{2}}{\partial b_{1 t}^{2}}\right]-\frac{M R S_{b_{1}, b_{2}}^{2, t}}{r_{t+1}}\left[\left(\tau_{x, t+1}-\frac{\mu_{t+1}}{\gamma_{t+1}}\right) \frac{\partial x_{2 t+1}^{2}}{\partial b_{2 t+1}^{2}}+\tau_{y, t+1} \frac{\partial y_{2 t+1}^{2}}{\partial b_{2 t+1}^{2}}\right]
\end{aligned}
$$

To interpret equations (46), consider first the special case without any consumption externality, and where the two commodity taxes are zero (which in terms of the formulas presented above 
would imply $\left.\tau_{y, t}=\tau_{x, t}=\mu_{t} / \gamma_{t}=\tau_{y, t+1}=\tau_{x, t+1}=\mu_{t+1} / \gamma_{t+1}=0\right)$. Then, if leisure is separable from the other goods in the utility function such that $M R S_{b_{1}, b_{2}}^{1, t}=\overline{M R S}_{b_{1}, b_{2}}^{2, t}$ (meaning that the low-ability type and the mimicker experience the same tradeoff between present and future consumption), both marginal capital income tax rates would be zero. Therefore, this special case reproduces Ordover and Phelps' (1979) result showing when a government has no need for capital income taxation, if the labor income tax is optimal. ${ }^{40}$

With reference to the special case referred to above, the first term on the right hand side of equation (46a) follows by relaxing the assumption that leisure is separable from the other goods in the utility function, implying that the government may relax the self-selection constraint by exploiting that the low-ability type and the mimicker typically differ in their desired tradeoff between present and future consumption (due to that they differ in terms of leisure time). If the marginal rate of substitution between the present and future consumption space decreases (increases) with the time spent on leisure, there is an incentive for the government to stimulate (counteract) the current consumption through a marginal savings tax (subsidy) on the low-ability type. ${ }^{41}$ There is no corresponding component in the marginal capital income tax formula for the high-ability type.

Let us now return to the general model, which contains an environmental externality (such that $\mu_{t} / \gamma_{t} \neq 0$ for all $t$ ), and where commodity taxes are used alongside the two income taxes. Two results follow directly by comparing equations (45) and (46). First, the optimal marginal capital income tax rates do not depend directly on the social shadow price of the stock of pollution, meaning that the environmental externality does not directly affect the policy rules for marginal capital income taxation. This is seen from equation (45a) by noticing that $\tau_{x, t}-\mu_{t} / \gamma_{t}$ and $\tau_{x, t+1}-\mu_{t+1} / \gamma_{t+1}$ do not depend directly on $\mu_{t} / \gamma_{t}$ and $\mu_{t+1} / \gamma_{t+1}$, respectively. In our quite general model, this result enables us to verify the additivity property: the social value of a decrease in the stock of pollution enters additively in the commodity tax formula for the dirty good, while it neither affects the tax policy rule for the clean good nor the policy rules for

\footnotetext{
${ }^{40}$ Note that equations (46) are derived by using the social first-order conditions for $b_{1 t}^{j}, j=1,2$, which, in turn, are necessary conditions for an optimal labor income tax.

${ }^{41}$ See Brett (1997).
} 
marginal labor and capital income taxation. This shows that the additivity property carries over to an intertemporal model with a stock-externality, as long as the externality is atmospheric.

Second, and by analogy to the discussion of marginal income taxation in the benchmark model, note that the terms in the second row of equation (46a), and the whole right hand side of equation (46b), reflect the fact that the commodity taxes are typically distortionary at the second-best optimum, i.e., $\tau_{x, t} \neq \mu_{t} / \gamma_{t}$ and $\tau_{y, t} \neq 0$. The marginal capital income tax policy partly compensates for these distortions. To see this more clearly, suppose that $\tau_{x, t}>\mu_{t} / \gamma_{t}$ at the second-best optimum, implying that the commodity tax on the dirty good is set at a higher rate in period $t$ than motivated by externality correction. It is for this reason desirable to stimulate the consumption of the dirty good. Therefore, as long as the dirty good is normal in the sense that $\partial x_{1 t}^{j} / \partial b_{1 t}^{j}>0$, there is a policy incentive to increase the available consumption space for young individuals by inducing them to save less. On the margin, this can be accomplished through a higher marginal capital income tax rate. By a similar argument, if $\tau_{x, t}<\mu_{t} / \gamma_{t}$, there would be an incentive to implement a lower marginal capital income tax rate to reduce the consumption space available to young individuals and thus also reduce the consumption of the dirty good. This effect is captured by the first term in the second row of equation (46a) and the first term on the right hand side of equation (46b), respectively. The interpretation of the component $\tau_{y, t} \partial y_{1 t}^{j} / \partial b_{1 t}^{j}$ is analogous.

Terms inside the second square bracket on the right hand side of equations (46a) and (46b) are interpretable along similar lines. If, for example, $\tau_{x, t+1}<\mu_{t+1} / \gamma_{t+1}$, the commodity tax on the dirty good in period $t+1$ is set at a lower rate than motivated by externality correction. It is for this reason welfare improving to reduce the consumption of the dirty good in period $t+1$. As long as the dirty good is normal, this can be accomplished by inducing the individuals to save less in period $t$, which is achieved by implementing a higher marginal capital income tax rate. Note finally that the second row of equation (46a) and the whole right hand side of equation (46b) would vanish if leisure is weakly separable from the other goods in the utility function, since the commodity taxes are non-distortionary and satisfy $\tau_{x, t}=\mu_{t} / \gamma_{t}$ and $\tau_{y, t}=0$ for all $t$ in this special case. 
Let us end by briefly discussing the consequences of replacing the atmospheric pollution externality with a non-atmospheric externality (such that the individuals contribute differently to the pollution-flow through their consumption of the dirty good). Based on the reasoning in subsection 4.1, we know that the linear tax on the dirty good would not be a sufficiently flexible instrument for internalizing this externality. The implications for the tax on the clean good and the marginal labor income taxes were discussed at some length in subsection 4.1, and these qualitative conclusions carry over to the intertemporal model analyzed here. However, a nonatmospheric externality would in this broader framework also imply a corrective motive for marginal capital income taxation. The explicit details of the environmental motive behind capital taxation in the presence of a non-atmospheric externality is beyond the scope of this paper but to illustrate the idea, let us consider the following example. From the analysis in subsection 4.1 we know that if $\alpha^{1}>\alpha^{2}$ (i.e., if the low-ability type's marginal contribution to the externality exceeds that of the high-ability type), then the corrective part of the commodity tax on the dirty good falls short of the marginal social damage generated by the low-ability type's consumption, while it exceeds the marginal social damage generated by the high-ability type's consumption (see equations [20]). If the income effect on dirty goods consumption varies over time for each type, we conjecture that the government may use marginal capital income taxation to reallocate each type's consumption over time in order to reduce the marginal damage generated by the lowability type relative to the marginal damage generated by the high-ability type.

\section{Discussion}

This paper has analyzed optimal taxation under environmental externalities, where we focused on mixed tax problems in various settings with asymmetric information between the government and the private sector. Mixed taxation is meant to imply that the set of policy instruments includes nonlinear income taxes and linear commodity taxes, which gives a realistic description of real world tax systems. It also implies that tax distortions are interpretable as outcomes of optimal policy choices subject to information limitations instead of as outcomes of restrictions on the available policy instruments. 
We started by discussing a static benchmark model, which distinguishes between two consumertypes (based on earnings-ability) as well as between clean consumption goods and an environmentally dirty good, and where the aggregate consumption of the dirty good causes a negative environmental externality. In this standard setting, where the externality is atmospheric in nature, the main environmental policy message is that of targeting: the social value of a cleaner environment enters additively in the tax formula for the dirty good, while it does not affect the policy rules for taxes on clean goods or marginal income taxation. The intuition is, of course, that a linear tax on the dirty good constitutes a perfect instrument for externality correction under an atmospheric externality, meaning that the policy rules for the other tax instruments take the same general form as in the absence of any externality. As we are considering a second-best setting with asymmetric information, note that the social value of a cleaner environment does not only reflect the (Pigouvian) sum of marginal willingness to pay to avoid the externality. It also reflects how a change in the level of environmental damage affects the scope for redistribution (i.e., whether it relaxes or tightens the self-selection constraint). We also described how the marginal income tax and commodity tax structure reflects distributional concerns through an incentive to relax the self-selection constraint.

The paper also discussed several scenarios where the principle of targeting is not fully applicable. One such case is where the externality caused by dirty good consumption is non-atmospheric, in which the marginal contribution to the externality differs among individuals. Another is the presence of border-trade in the dirty good. In these scenarios, it follows that a linear tax on the dirty good is not a flexible enough instrument for internalizing the externality, which means that taxes on clean goods as well as the income tax will serve as supplemental instruments for externality-correction. The structure of the taxation of clean goods and income will then depend on whether the clean goods are complementary with or substitutable for the dirty good, and whether leisure is complementary with or substitutable for the dirty good, respectively. We also considered a model with two countries and a global externality caused by the aggregate consumption of the dirty good measured over both countries, where the principle of targeting fails in a non-cooperative Nash-equilibrium because of strategic interaction. 
In the final part of the paper, we extended the analysis to an OLG model with stock-pollution, allowing us to integrate the study of optimal redistributive taxation under environmental externalities (which is often based on static models) in an intertemporal framework. Although this model bears a close resemblance to models used in earlier literature on optimal taxation in dynamic economies, it is to our knowledge novel in this particular context with an environmental externality, where the government raises revenue by means of commodity taxation, labor income taxation, and capital income taxation. By analogy to the benchmark model, we considered a case where the externality caused by the stock of pollution is atmospheric, and showed that the principle of targeting carries over to this dynamic economy; in other words, the social value of a decrease in the stock of pollution enters additively in the tax policy rule for the dirty good, while it has no direct effect in the tax policy rules for clean goods or the policy rules for marginal labor and capital income taxation. Yet, the appearance of stock-pollution also modifies the results in a fundamental way, since an increase in the consumption of the dirty good at any time leads to a permanent increase in the stock of pollution. The marginal social value of a decrease in the stock of pollution will thus depend on all future generations' marginal willingness to pay to avoid pollution, as well as on the self-selection constraints underlying the redistribution policy in all future periods.

There are many possible avenues for future research, and we shall briefly hint at two of them. First, although the principle of targeting is the most important practical policy message of the benchmark model, this principle may not be applicable in real world economies for a variety of reasons. In our view, this exemplifies a relevant area for future research, where our brief discussions in Sections 4 and 5 are far from exhaustive. Second, in real world economies, several environmental externalities are often present at the same time and may interact in various ways. We have focused on model economies with one single source of environmental damage and thus completely neglected such interactions throughout the paper, primarily because their implications for optimal redistributive taxation have not yet been thoroughly examined. We hope to be able to address these issues, as well as questions related to them, in future research.

\section{Appendix}

Derivation of the Shadow Price in Equation (12) 
To derive equation (12), first substitute $v_{E}^{j}=-M W P_{E, b}^{j} v_{b}^{j}$ and $\hat{v}_{E}^{2}=-\widehat{M W P}_{E, b}^{2} \hat{v}_{b}^{2}$ into (11g) and rearrange. This gives

$$
\mu=v_{b}^{1} M W P_{E, b}^{1}+(\eta+\lambda) v_{b}^{2} M W P_{E, b}^{2}-\lambda \hat{v}_{b}^{2} \widehat{M W P_{E, b}^{2}}-\gamma\left(t_{x}-\frac{\mu}{\gamma}\right) \sum_{j} \frac{\partial x^{j}}{\partial E}-\gamma t_{y} \sum_{j} \frac{\partial y^{j}}{\partial E} .
$$

Next, use (11a) to solve for $v_{b}^{1}$ and (11c) to solve for $(\eta+\lambda) v_{b}^{2}$. Substituting the resulting expressions into (A.1), dividing by $\gamma$, and solving for $\mu / \gamma$ gives equation (12) in the text.

\section{Derivation of the Commodity Tax Formulas in Equations (14a) and (14b)}

To derive the commodity tax formulas, we first multiply (11a) by $x^{1}$ and add the resulting expression to (11e). Then we multiply (11c) by $x^{2}$ and add the resulting expression to (11e). Similarly, we multiply (11a) by $y^{1}$ and add the resulting expression to (11f). Then we multiply (11c) by $y^{2}$ and add the resulting expression to (11f). This gives the following equation system:

$$
\left[\begin{array}{ll}
\sum_{j} \frac{\partial \tilde{x}^{j}}{\partial q_{x}} & \sum_{j} \frac{\partial \tilde{y}^{j}}{\partial q_{x}} \\
\sum_{j} \frac{\partial \tilde{x}^{j}}{\partial q_{y}} & \sum_{j} \frac{\partial \tilde{y}^{j}}{\partial q_{y}}
\end{array}\right] \cdot\left[\begin{array}{l}
t_{x} \\
t_{y}
\end{array}\right]=\left[\begin{array}{l}
\frac{\mu}{\gamma} \sum_{j} \frac{\partial \tilde{x}^{j}}{\partial q_{x}}-\frac{\lambda \hat{v}_{b}^{2}}{\gamma}\left(\hat{x}^{2}-x^{1}\right) \\
\frac{\mu}{\gamma} \sum_{j} \frac{\partial \tilde{x}^{j}}{\partial q_{y}}-\frac{\lambda \hat{v}_{b}^{2}}{\gamma}\left(\hat{y}^{2}-y^{1}\right)
\end{array}\right] .
$$

$\Omega$ in the text is the determinant of the first matrix on the left hand side in (A.2). Using Cramer's rule to solve for $t_{x}$ and $t_{y}$ produces equations (14a) and (14b) in the text.

Derivation of the Marginal Income Tax Formulas in Equations (17a) and (17b)

To derive (17a), we first use (11a) to solve for $v_{b}^{1}$ and then use (11b) to solve for $v_{z}^{1}$. Dividing the expression for $v_{z}^{1}$ by the expression for $v_{b}^{1}$, and using that $M R S_{z, b}^{1}=v_{z}^{1} / v_{b}^{1}$, produces

$$
M R S_{z, b}^{1}=\frac{\lambda \phi \hat{v}_{z}^{2}+\gamma\left(w^{1}-t_{x} \frac{\partial x^{1}}{\partial z^{1}}-t_{y} \frac{\partial y^{1}}{\partial z^{1}}\right)+\mu \frac{\partial x^{1}}{\partial z^{1}}}{\lambda \hat{v}_{b}^{2}+\gamma\left(1-t_{x} \frac{\partial x^{1}}{\partial b^{1}}-t_{y} \frac{\partial y^{1}}{\partial b^{1}}\right)+\mu \frac{\partial x^{1}}{\partial b^{1}}} .
$$

Multiply both sides of (A.3) by the expression in the denominator on the right hand side. By rearranging the resulting expression and dividing by $\gamma$, we obtain

$$
0=\frac{\lambda \hat{v}_{b}^{2}}{\gamma}\left(M R S_{z, b}^{1}-\phi \frac{\hat{v}_{z}^{2}}{\hat{v}_{b}^{2}}\right)-\left(w^{1}-M R S_{z, b}^{1}\right)+\left(t_{x}-\frac{\mu}{\gamma}\right) \frac{\partial \tilde{x}^{1}}{\partial z^{1}}+t_{y} \frac{\partial \tilde{y}^{1}}{\partial z^{1}} .
$$

Use that the private first-order condition for the hours of work in equation (5) can be written as $w^{1}-M R S_{z, b}^{1}=$ $T_{I}^{1} w^{1}$. Substituting this expression into (A.4) and solving for $T_{I}^{1}$ gives equation (17a) in the text. Equation (17b) is derived analogously.

Solving the Government's Problem in the Model with Transboundary Environmental Damage

The first-order conditions for government $i$ become (government $k$ 's first-order conditions are analogous)

$$
\begin{aligned}
& \frac{\partial L^{i}}{\partial b^{i, 1}}=v_{b}^{i, 1}-\lambda^{i} \hat{v}_{b}^{i, 2}+\gamma^{i}\left(t_{x}^{i} \frac{\partial x^{i, 1}}{\partial b^{i, 1}}-1\right)-\mu^{i} \frac{\partial x^{i, 1}}{\partial b^{i, 1}}+\frac{\partial L^{i}}{\partial p_{x}} \frac{\partial p_{x}}{\partial b^{i, 1}}=0 \\
& \frac{\partial L^{i}}{\partial l^{i, 1}}=-v_{z}^{i, 1}+\lambda^{i} \hat{v}_{z}^{i, 2}\left(\phi^{i}+l^{i, 1} \frac{\partial \phi^{i}}{\partial l^{i, 1}}\right)+\gamma^{i}\left(w^{i, 1}-t_{x}^{i} \frac{\partial x^{i, 1}}{\partial z^{i, 1}}\right)+\mu^{i} \frac{\partial x^{i, 1}}{\partial z^{i, 1}}+\frac{\partial L^{i}}{\partial p_{x}} \frac{\partial p_{x}}{\partial l^{i, 1}}=0 \\
& \frac{\partial L^{i}}{\partial b^{i, 2}}=\left(\eta^{i}+\lambda^{i}\right) v_{b}^{i, 2}+\gamma^{i}\left(t_{x}^{i} \frac{\partial x^{i, 2}}{\partial b^{i, 2}}-1\right)-\mu^{i} \frac{\partial x^{i, 2}}{\partial b^{i, 2}}+\frac{\partial L^{i}}{\partial p_{x}} \frac{\partial p_{x}}{\partial b^{i, 2}}=0 \\
& \frac{\partial L^{i}}{\partial l^{i, 2}}=-\left(\eta^{i}+\lambda^{i}\right) v_{z}^{i, 2}+\lambda^{i} \hat{v}_{z}^{i, 2} l^{i, 1} \frac{\partial \phi^{i}}{\partial l^{i, 2}}+\gamma^{i}\left(w^{i, 2}-t_{x}^{i} \frac{\partial x^{i, 2}}{\partial z^{i, 2}}\right)+\mu^{i} \frac{\partial x^{i, 2}}{\partial z^{i, 2}}+\frac{\partial L^{i}}{\partial p_{x}} \frac{\partial p_{x}}{\partial l^{i, 2}}=0
\end{aligned}
$$




$$
\begin{aligned}
& \frac{\partial L^{i}}{\partial t_{x}^{i}}=\left(\gamma^{i}-v_{b}^{i, 1}\right) x^{i, 1}+\left[\gamma^{i}-\left(\eta^{i}+\lambda^{i}\right) v_{b}^{i, 2}\right] x^{i, 2}+\lambda^{i} \hat{v}_{b}^{i, 2} \hat{x}^{i, 2}+\gamma^{i}\left(t_{x}^{i}-\frac{\mu^{i}}{\gamma^{i}}\right) \sum_{j} \frac{\partial x^{i, j}}{\partial q_{x}^{i}}+\frac{\partial L^{i}}{\partial p_{x}} \frac{\partial p_{x}}{\partial t_{x}^{i}}=0 \\
& \frac{\partial L^{i}}{\partial E}=v_{E}^{i, 1}+\left(\eta^{i}+\lambda^{i}\right) v_{E}^{i, 2}-\lambda^{i} \hat{v}_{E}^{i, 2}+\mu^{i}\left(1-\sum_{j} \frac{\partial x^{i, j}}{\partial E}-\sum_{j} \frac{\partial x^{k, j}}{\partial E}\right)+\gamma^{i} t_{x}^{i} \sum_{j} \frac{\partial x^{i, j}}{\partial E}+\frac{\partial L^{i}}{\partial p_{x}} \frac{\partial p_{x}}{\partial E}=0
\end{aligned}
$$

where

$$
\frac{\partial L^{i}}{\partial p_{x}}=A^{i}+\gamma^{i} N X^{i}+\lambda^{i} \hat{v}_{z}^{i, 2} l^{i, 1} \frac{\partial \phi^{i}}{\partial p_{x}}-\mu^{i} \sum_{j} \frac{\partial x^{k, j}}{\partial q_{x}^{i}}
$$

and

$$
A^{i}=\left(\gamma^{i}-v_{b}^{i, 1}\right) x^{i, 1}+\left[\gamma^{i}-\left(\eta^{i}+\lambda^{i}\right) v_{b}^{i, 2}\right] x^{i, 2}+\lambda^{i} \hat{v}_{b}^{i, 2} \hat{x}^{i, 2}+\gamma^{i}\left(t_{x}^{i}-\frac{\mu^{i}}{\gamma^{i}}\right) \sum_{j} \frac{\partial x^{i, j}}{\partial q_{x}^{i}} .
$$

$N X^{i}=S_{x}^{i}-\sum_{j} x^{i, j}$ is country $i^{\prime}$ s net export of the dirty good. By substituting the definition of $A^{i}$ into (A.9), we can write equation (A.9) as $A^{i}+\frac{\partial L^{i}}{\partial p_{x}} \frac{\partial p_{x}}{\partial t_{x}^{i}}=0$. Using this expression to replace $A^{i}$ in (A.11), and solving for $\frac{\partial L^{i}}{\partial p_{x}}$ in the resulting expression, gives equation (30) in the text.

To derive the commodity tax formula in equation (28), we first multiply (A.5) by $x^{i, 1}$ and (A.7) by $x^{i, 2}$. Then we add the resulting expressions to (A.9). This produces

$$
0=\lambda^{i} \hat{v}_{b}^{i, 2}\left(\hat{x}^{i, 2}-x^{i, 1}\right)+\gamma^{i}\left(t_{x}^{i}-\frac{\mu^{i}}{\gamma^{i}}\right) \sum_{j} \frac{\partial \tilde{x}^{i, j}}{\partial q_{x}^{i}}+\frac{\partial L^{i}}{\partial p_{x}}\left(\frac{\partial p_{x}}{\partial t_{x}^{i}}+\frac{\partial p_{x}}{\partial b^{i, 1}} x^{i, 1}+\frac{\partial p_{x}}{\partial b^{i, 2}} x^{i, 2}\right) .
$$

Next, observe that the equilibrium condition defined in equation (27) implies

$$
\frac{\partial p_{x}}{\partial t_{x}^{i}}=\frac{\sum_{j} \partial x^{i, j} / \partial q_{x}^{i}}{\beta^{i}}<0, \quad \frac{\partial p_{x}}{\partial b^{i, j}}=\frac{\partial x^{i, j} / \partial b^{i, j}}{\beta^{i}}>0 .
$$

By using the expressions in (A.13), the expression inside the third parenthesis in (A.12) can be written as

$$
\frac{\partial p_{x}}{\partial t_{x}^{i}}+\frac{\partial p_{x}}{\partial b^{i, 1}} x^{i, 1}+\frac{\partial p_{x}}{\partial b^{i, 2}} x^{i, 2}=\frac{1}{\beta^{i}} \sum_{j} \frac{\partial \tilde{x}^{i, j}}{\partial q_{x}^{i}} .
$$

Substituting (A.14) into (A.12) and solving for $t_{x}^{i}$ gives

$$
t_{x}^{i}=\frac{\mu^{i}}{\gamma^{i}}+\frac{\lambda^{i, *}}{\sum_{j} \partial \tilde{x}^{i, j} / \partial q_{x}^{i}}\left(x^{i, 1}-\hat{x}^{i, 2}\right)-\frac{\partial L^{i}}{\partial p_{x}} \frac{1}{\beta^{i} \gamma^{i}} .
$$

Finally, substituting equation (A11) into (A.15) produces equation (28) in the text.

To derive (31a), we proceed in the same way as when we derived equation (17a). The analogue to equation (A.4) then becomes

$$
0=\lambda^{i, *}\left(M R S_{z, b}^{i, 1}-\phi^{i} \widehat{M R S}_{z, b}^{i, 2}-\widehat{M R S}_{z, b}^{i, 2} l^{i, 1} \frac{\partial \phi^{i}}{\partial l^{i, 1}}\right)-\left(w^{i, 1}-M R S_{z, b}^{i, 1}\right)+\left(t_{x}^{i}-\frac{\mu^{i}}{\gamma^{i}}\right) \frac{\partial \tilde{x}^{i, 1}}{\partial z^{i, 1}}-\frac{1}{\gamma^{i}} \frac{\partial L^{i}}{\partial p_{x}}\left(\frac{\partial p_{x}}{\partial l^{i, 1}}+\frac{\partial p_{x}}{\partial b^{i, 1}} M R S_{z, b}^{i, 1}\right) .
$$

Substituting $w^{i, 1}-M R S_{z, b}^{i, 1}=T_{I}^{i, 1} w^{i, 1}$ into this expression and solving for $T_{I}^{i, 1}$ produces

$$
T_{I}^{i, 1}=\frac{\lambda^{i, *}}{w^{i, 1}}\left(M R S_{z, b}^{i, 1}-\phi^{i} \widehat{M R S}_{z, b}^{i, 2}-\widehat{M R S}_{z, b}^{i, 2} l^{i, 1} \frac{\partial \phi^{i}}{\partial l^{i, 1}}\right)+\left(t_{x}^{i}-\frac{\mu^{i}}{\gamma^{i}}\right) \frac{1}{w^{i, 1}} \frac{\partial \tilde{x}^{i, 1}}{\partial z^{i, 1}}-\frac{1}{w^{i, 1} \gamma^{i}} \frac{\partial L^{i}}{\partial p_{x}}\left(\frac{\partial p_{x}}{\partial l^{i, 1}}+\frac{\partial p_{x}}{\partial b^{i, 1}} M R S_{z, b}^{i, 1}\right) .
$$

To evaluate the expression inside the last parenthesis on the right hand side of (A.16), we observe that 


$$
\frac{\partial p_{x}}{\partial l^{i, 1}}=-\frac{\partial S_{x}^{i} / \partial l^{i, 1}+\partial x^{i, 1} / \partial z^{i, 1}}{\beta^{i}}, \quad \frac{\partial p_{x}}{\partial b^{i, 1}}=\frac{\partial x^{i, 1} / \partial b^{i, 1}}{\beta^{i}}>0, \quad \frac{\partial \tilde{x}^{j}}{\partial z^{j}}=\frac{\partial x^{j}}{\partial z^{j}}-\frac{\partial x^{j}}{\partial b^{j}} M R S_{z, b}^{j} .
$$

Substituting these expressions into the last parenthesis on the right hand side of (A.16) produces equation (31a) in the text. Equation (31b) is derived analogously.

Solving the Government's Problem in the Overlapping Generations Model with a Stock-Externality

The government's first-order conditions at an arbitrary point in time $t$ become

$$
\begin{aligned}
& \frac{\partial L_{0}}{\partial b_{1 t}^{1}}=\frac{\partial W}{\partial V_{t}} \frac{\partial v_{1 t}^{1}}{\partial b_{1 t}^{1}}-\lambda_{t} \frac{\partial \hat{v}_{1 t}^{2}}{\partial b_{1 t}^{1}}+\gamma_{t}\left(\tau_{x, t} \frac{\partial x_{1 t}^{1}}{\partial b_{1 t}^{1}}+\tau_{y, t} \frac{\partial y_{1 t}^{1}}{\partial b_{1 t}^{1}}-1\right)-\mu_{t} \frac{\partial x_{1 t}^{1}}{\partial b_{1 t}^{1}}=0 \\
& \frac{\partial L_{0}}{\partial b_{2 t+1}^{1}}=\frac{\partial W}{\partial V_{t}} \beta \frac{\partial v_{2 t+1}^{1}}{\partial b_{2 t+1}^{1}}-\lambda_{t} \beta \frac{\partial \hat{v}_{2 t+1}^{2}}{\partial b_{2 t+1}^{1}}+\gamma_{t+1}\left(\tau_{x, t+1} \frac{\partial x_{2 t+1}^{1}}{\partial b_{2 t+1}^{1}}+\tau_{y, t+1} \frac{\partial y_{2 t+1}^{1}}{\partial b_{2 t+1}^{1}}-1\right)-\mu_{t+1} \frac{\partial x_{2 t+1}^{1}}{\partial b_{2 t+1}^{1}}=0 \\
& \frac{\partial L_{0}}{\partial l_{1 t}^{1}}=-\frac{\partial W}{\partial v_{t}} \frac{\partial v_{1 t}^{1}}{\partial z_{1 t}^{1}}+\lambda_{t} \phi \frac{\partial \hat{v}_{1 t}^{2}}{\partial \hat{z}_{1 t}^{2}}+\gamma_{t}\left(w_{1 t}^{1}-\tau_{x, t} \frac{\partial x_{1 t}^{1}}{\partial z_{1 t}^{1}}-\tau_{y, t} \frac{\partial y_{1 t}^{1}}{\partial z_{1 t}^{1}}\right)+\mu_{t} \frac{\partial x_{1 t}^{1}}{\partial z_{1 t}^{1}}=0 \\
& \frac{\partial L_{0}}{\partial b_{1 t}^{2}}=\left(\frac{\partial W}{\partial V_{t}}+\lambda_{t}\right) \frac{\partial v_{1 t}^{2}}{\partial b_{1 t}^{2}}+\gamma_{t}\left(\tau_{x, t} \frac{\partial x_{1 t}^{2}}{\partial b_{1 t}^{2}}+\tau_{y, t} \frac{\partial y_{1 t}^{2}}{\partial b_{1 t}^{2}}-1\right)-\mu_{t} \frac{\partial x_{1 t}^{2}}{\partial b_{1 t}^{2}}=0 \\
& \frac{\partial L_{0}}{\partial b_{2 t+1}^{2}}=\left(\frac{\partial W}{\partial v_{t}}+\lambda_{t}\right) \beta \frac{\partial v_{2 t+1}^{2}}{\partial b_{2 t+1}^{2}}+\gamma_{t+1}\left(\tau_{x, t+1} \frac{\partial x_{2 t+1}^{2}}{\partial b_{2 t+1}^{2}}+\tau_{y, t+1} \frac{\partial y_{2 t+1}^{2}}{\partial b_{2 t+1}^{2}}-1\right)-\mu_{t+1} \frac{\partial x_{2 t+1}^{2}}{\partial b_{2 t+1}^{2}}=0 \\
& \frac{\partial L_{0}}{\partial l_{1 t}^{2}}=-\left(\frac{\partial W}{\partial v_{t}}+\lambda_{t}\right) \frac{\partial v_{1 t}^{2}}{\partial z_{1 t}^{2}}+\gamma_{t}\left(w_{1 t}^{2}-\tau_{x, t} \frac{\partial x_{1 t}^{2}}{\partial z_{1 t}^{2}}-\tau_{y, t} \frac{\partial y_{1 t}^{2}}{\partial z_{1 t}^{2}}\right)-\mu_{t} \frac{\partial x_{1 t}^{2}}{\partial z_{1 t}^{2}}=0 \\
& \frac{\partial L_{0}}{\partial t_{x, t}}=-\frac{\partial W}{\partial V_{t}} x_{1 t}^{1} \frac{\partial v_{1 t}^{1}}{\partial b_{1 t}^{1}}+\lambda_{t} \hat{x}_{1 t}^{2} \frac{\partial \hat{v}_{1 t}^{2}}{\partial b_{1 t}^{1}}-\left(\frac{\partial W}{\partial V_{t}}+\lambda_{t}\right) x_{1 t}^{2} \frac{\partial v_{1 t}^{2}}{\partial b_{1 t}^{2}}-\frac{\partial W}{\partial V_{t-1}} x_{2 t}^{1} \beta \frac{\partial v_{2 t}^{1}}{\partial b_{2 t}^{1}}+\lambda_{t-1} \beta \hat{x}_{2 t}^{2} \frac{\partial \hat{v}_{2 t}^{2}}{\partial b_{2 t}^{1}}-\mu_{t} \sum_{j}\left(\frac{\partial x_{1 t}^{j}}{\partial q_{x, t}}+\frac{\partial x_{2 t}^{j}}{\partial q_{x, t}}\right) \\
& -\left(\frac{\partial W}{\partial V_{t-1}}+\lambda_{t-1}\right) x_{2 t}^{2} \beta \frac{\partial v_{2 t}^{2}}{\partial b_{2 t}^{2}}+\gamma_{t}\left[\sum_{j}\left(x_{1 t}^{j}+x_{2 t}^{j}\right)+\tau_{x, t} \sum_{j}\left(\frac{\partial x_{1 t}^{j}}{\partial q_{x, t}}+\frac{\partial x_{2 t}^{j}}{\partial q_{x, t}}\right)+\tau_{y, t} \sum_{j}\left(\frac{\partial y_{1 t}^{j}}{\partial q_{x, t}}+\frac{\partial y_{2 t}^{j}}{\partial q_{x, t}}\right)\right]=0 \\
& \frac{\partial L_{0}}{\partial t_{y, t}}=-\frac{\partial W}{\partial v_{t}} y_{1 t}^{1} \frac{\partial v_{1 t}^{1}}{\partial b_{1 t}^{1}}+\lambda_{t} \hat{y}_{1 t}^{2} \frac{\partial \hat{v}_{1 t}^{2}}{\partial b_{1 t}^{1}}-\left(\frac{\partial W}{\partial V_{t}}+\lambda_{t}\right) y_{1 t}^{2} \frac{\partial v_{1 t}^{2}}{\partial b_{1 t}^{2}}-\frac{\partial W}{\partial V_{t-1}} y_{2 t}^{1} \beta \frac{\partial v_{2 t}^{1}}{\partial b_{2 t}^{1}}+\lambda_{t-1} \beta \hat{y}_{2 t}^{2} \frac{\partial \hat{v}_{2 t}^{2}}{\partial b_{2 t}^{1}}-\mu_{t} \sum_{j}\left(\frac{\partial x_{1 t}^{j}}{\partial q_{y, t}}+\frac{\partial x_{2 t}^{j}}{\partial q_{y, t}}\right) \\
& -\left(\frac{\partial W}{\partial v_{t-1}}+\lambda_{t-1}\right) y_{2 t}^{2} \beta \frac{\partial v_{2 t}^{2}}{\partial b_{2 t}^{2}}+\gamma_{t}\left[\sum_{j}\left(y_{1 t}^{j}+y_{2 t}^{j}\right)+\tau_{x, t} \sum_{j}\left(\frac{\partial x_{1 t}^{j}}{\partial q_{y, t}}+\frac{\partial x_{2 t}^{j}}{\partial q_{y, t}}\right)+\tau_{y, t} \sum_{j}\left(\frac{\partial y_{1 t}^{j}}{\partial q_{y, t}}+\frac{\partial y_{2 t}^{j}}{\partial q_{y, t}}\right)\right]=0 \\
& \frac{\partial L_{0}}{\partial E_{t}}=\frac{\partial W}{\partial V_{t}} \frac{\partial v_{1 t}^{1}}{\partial E_{t}}-\lambda_{t} \frac{\partial \hat{v}_{1 t}^{2}}{\partial E_{t}}+\left(\frac{\partial W}{\partial V_{t}}+\lambda_{t}\right) \frac{\partial v_{1 t}^{2}}{\partial E_{t}}+\frac{\partial W}{\partial V_{t-1}} \beta \frac{\partial v_{2 t}^{1}}{\partial E_{t}}-\lambda_{t-1} \beta \frac{\partial \hat{v}_{2 t}^{2}}{\partial E_{t}}+\left(\frac{\partial W}{\partial V_{t-1}}+\lambda_{t-1}\right) \beta \frac{\partial v_{2 t}^{2}}{\partial E_{t}} \\
& +\mu_{t}-(1-\rho) \mu_{t+1}-\mu_{t} \sum_{j}\left(\frac{\partial x_{1 t}^{j}}{\partial E_{t}}+\frac{\partial x_{2 t}^{j}}{\partial E_{t}}\right)+\gamma_{t}\left[\tau_{x, t} \sum_{j}\left(\frac{\partial x_{1 t}^{j}}{\partial E_{t}}+\frac{\partial x_{2 t}^{j}}{\partial E_{t}}\right)+\tau_{y, t} \sum_{j}\left(\frac{\partial y_{1 t}^{j}}{\partial E_{t}}+\frac{\partial y_{2 t}^{j}}{\partial E_{t}}\right)\right]=0 \\
& \frac{\partial L_{0}}{\partial K_{t+1}}=\gamma_{t+1}\left(1+r_{t+1}\right)-\gamma_{t}=0 .
\end{aligned}
$$

To derive equation (44), we first rewrite (A.17), (A.18), (A.20) and (A.21) to read (where (A.18) and (A.20) have been lagged one period)

$$
\begin{aligned}
& \frac{\partial W}{\partial V_{t}} \frac{\partial v_{1 t}^{1}}{\partial b_{1 t}^{1}}=\lambda_{t} \frac{\partial \hat{v}_{1 t}^{2}}{\partial b_{1 t}^{1}}-\gamma_{t}\left(\tau_{x, t} \frac{\partial x_{1 t}^{1}}{\partial b_{1 t}^{1}}+\tau_{y, t} \frac{\partial y_{1 t}^{1}}{\partial b_{1 t}^{1}}-1\right)+\mu_{t} \frac{\partial x_{1 t}^{1}}{\partial b_{1 t}^{1}} \\
& \frac{\partial W}{\partial V_{t-1}} \beta \frac{\partial v_{2 t}^{1}}{\partial b_{2 t}^{1}}=\lambda_{t-1} \beta \frac{\partial \hat{v}_{2 t}^{2}}{\partial b_{2 t}^{1}}-\gamma_{t}\left(\tau_{x, t} \frac{\partial x_{2 t}^{1}}{\partial b_{2 t}^{1}}+\tau_{y}, \frac{\partial y_{2 t}^{1}}{\partial b_{2 t}^{1}}-1\right)+\mu_{t} \frac{\partial x_{2 t}^{1}}{\partial b_{2 t}^{1}} \\
& \left(\frac{\partial W}{\partial V_{t}}+\lambda_{t}\right) \frac{\partial v_{1 t}^{2}}{\partial b_{1 t}^{2}}=-\gamma_{t}\left(\tau_{x, t} \frac{\partial x_{1 t}^{2}}{\partial b_{1 t}^{2}}+\tau_{y, t} \frac{\partial y_{1 t}^{2}}{\partial b_{1 t}^{2}}-1\right)+\mu_{t} \frac{\partial x_{1 t}^{2}}{\partial b_{1 t}^{2}} \\
& \left(\frac{\partial W}{\partial V_{t-1}}+\lambda_{t-1}\right) \beta \frac{\partial v_{2 t}^{2}}{\partial b_{2 t}^{2}}=-\gamma_{t}\left(\tau_{x, t} \frac{\partial x_{2 t}^{2}}{\partial b_{2 t}^{2}}+\tau_{y, t} \frac{\partial y_{2 t}^{2}}{\partial b_{2 t}^{2}}-1\right)+\mu_{t} \frac{\partial x_{2 t}^{2}}{\partial b_{2 t}^{2}} .
\end{aligned}
$$


Use $\frac{\partial v_{1 t}^{1}}{\partial E_{t}}=-\frac{\partial v_{1 t}^{1}}{\partial b_{1 t}^{1}} M W P_{1 t}^{1}, \frac{\partial v_{1 t}^{2}}{\partial E_{t}}=-\frac{\partial v_{1 t}^{2}}{\partial b_{1 t}^{2}} M W P_{1 t}^{2}, \frac{\partial v_{2 t}^{1}}{\partial E_{t}}=-\frac{\partial v_{2 t}^{1}}{\partial b_{2 t}^{1}} M W P_{2 t}^{1}, \frac{\partial v_{2 t}^{2}}{\partial E_{t}}=-\frac{\partial v_{2 t}^{2}}{\partial b_{2 t}^{2}} M W P_{2 t}^{2}, \frac{\partial \hat{v}_{1 t}^{2}}{\partial E_{t}}=-\frac{\partial \hat{v}_{1 t}^{2}}{\partial b_{1 t}^{1}} \widehat{M W P_{1 t}^{2}}$ and $\frac{\partial \hat{v}_{2 t}^{2}}{\partial E_{t}}=-\frac{\partial \hat{v}_{2 t}^{2}}{\partial b_{2 t}^{1}} \widehat{M W P_{2 t}^{2}}$. Combining these expressions with (A.27) - (A.30) in (A.25), and dividing by $\gamma_{t}$, gives

$$
\begin{aligned}
\frac{\mu_{t}}{\gamma_{t}} & =\sigma_{t}\left[\sum_{j}\left(M W P_{1 t}^{j}+M W P_{2 t}^{j}\right)-\tau_{x, t} \sum_{j}\left(\frac{\partial \tilde{x}_{1 t}^{j}}{\partial E_{t}}+\frac{\partial \tilde{x}_{2 t}^{j}}{\partial E_{t}}\right)-\tau_{y, t} \sum_{j}\left(\frac{\partial \tilde{y}_{1 t}^{j}}{\partial E_{t}}+\frac{\partial \tilde{y}_{2 t}^{j}}{\partial E_{t}}\right)\right] \\
& +\sigma_{t}\left[\lambda_{1 t}^{*}\left(M W P_{1 t}^{1}-\widehat{M W P_{1 t}^{2}}\right)+\lambda_{2 t}^{*}\left(M W P_{2 t}^{1}-\widehat{M W P_{2 t}^{2}}\right)\right]+\sigma_{t} \frac{(1-\rho)}{\left(1+r_{t+1}\right)} \frac{\mu_{t+1}}{\gamma_{t+1}}
\end{aligned}
$$

where we have used $\gamma_{t}=\gamma_{t+1}\left(1+r_{t+1}\right)$ and where

$$
\frac{1}{\sigma_{t}}=1-\frac{\partial \tilde{x}_{1 t}^{1}}{\partial E_{t}}-\frac{\partial \tilde{x}_{1 t}^{2}}{\partial E_{t}}-\frac{\partial \tilde{x}_{2 t}^{1}}{\partial E_{t}}-\frac{\partial \tilde{x}_{2 t}^{2}}{\partial E_{t}}, \quad \lambda_{1 t}^{*}=\frac{\lambda_{t}}{\gamma_{t}} \frac{\partial \hat{v}_{1 t}^{2}}{\partial b_{1 t}^{1}}, \quad \lambda_{2 t}^{*}=\beta \frac{\lambda_{t-1}}{\gamma_{t}} \frac{\partial \hat{v}_{2 t}^{2}}{\partial b_{2 t}^{1}}
$$

Forward (A.31) one period and substitute the resulting expression for $\mu_{t+1} / \gamma_{t+1}$ back into (A.31)

$$
\begin{aligned}
\frac{\mu_{t}}{\gamma_{t}} & =\sigma_{t} \sum_{j}\left(M W P_{1 t}^{j}+M W P_{2 t}^{j}\right)+\sigma_{t} \sigma_{t+1} \frac{(1-\rho)}{\left(1+r_{t+1}\right)} \sum_{j}\left(M W P_{1 t+1}^{j}+M W P_{2 t+1}^{j}\right) \\
& +\sigma_{t}\left[\lambda_{1 t}^{*}\left(M W P_{1 t}^{1}-\widehat{M W P} P_{1 t}^{2}\right)+\lambda_{2 t}^{*}\left(M W P_{2 t}^{1}-\widehat{M W P_{2 t}^{2}}\right)\right] \\
& +\sigma_{t} \sigma_{t+1} \frac{(1-\rho)}{\left(1+r_{t+1}\right)}\left[\lambda_{1 t+1}^{*}\left(M W P_{1 t+1}^{1}-\widehat{M W P_{1 t+1}^{2}}\right)+\lambda_{2 t+1}^{*}\left(M W P_{2 t+1}^{1}-\widehat{\left.\left.M W P_{2 t+1}^{2}\right)\right]}\right.\right. \\
& -\sigma_{t} \tau_{x, t} \sum_{j}\left(\frac{\partial \tilde{x}_{1 t}^{j}}{\partial E_{t}}+\frac{\partial \tilde{x}_{2 t}^{j}}{\partial E_{t}}\right)-\sigma_{t} \sigma_{t+1} \frac{(1-\rho)}{\left(1+r_{t+1}\right)} \tau_{x, t+1} \sum_{j}\left(\frac{\partial \tilde{x}_{1 t+1}^{j}}{\partial E_{t+1}}+\frac{\partial \tilde{x}_{2 t+1}^{j}}{\partial E_{t+1}}\right) \\
& -\sigma_{t} \tau_{y, t} \sum_{j}\left(\frac{\partial \tilde{y}_{1 t}^{j}}{\partial E_{t}}+\frac{\partial \tilde{y}_{2 t}^{j}}{\partial E_{t}}\right)-\sigma_{t} \sigma_{t+1} \frac{(1-\rho)}{\left(1+r_{t+1}\right)} \tau_{y, t+1} \sum_{j}\left(\frac{\partial \tilde{y}_{1 t+1}^{j}}{\partial E_{t+1}}+\frac{\partial \tilde{y}_{2 t+1}^{j}}{\partial E_{t+1}}\right)+\sigma_{t} \sigma_{t+1} \frac{(1-\rho)^{2}}{\left(1+r_{t+1}\right)\left(1+r_{t+2}\right)} \frac{\mu_{t+2}}{\gamma_{t+2}} .
\end{aligned}
$$

Summing over $\bar{n}$ periods implies

$$
\begin{aligned}
\frac{\mu_{t}}{\gamma_{t}} & =\sum_{n=0}^{\bar{n}} \frac{(1-\rho)^{n} \prod_{i=0}^{n} \sigma_{t+i}}{\prod_{i=1}^{n}\left(1+r_{t+i}\right)} \sum_{j}\left(M W P_{1 t+n}^{j}+M W P_{2 t+n}^{j}\right)+\frac{(1-\rho)^{\bar{n}} \prod_{i=0}^{\bar{n}} \sigma_{t+i}}{\prod_{i=1}^{\bar{n}}\left(1+r_{t+i}\right)} \frac{\mu_{t+\bar{n}}}{\gamma_{t+\bar{n}}} \\
& +\sum_{n=0}^{\bar{n}} \frac{(1-\rho)^{n} \prod_{i=0}^{n} \sigma_{t+i}}{\prod_{i=1}^{n}\left(1+r_{t+i}\right)}\left[\lambda_{t+n}^{*}\left(M W P_{1 t+n}^{1}-\widehat{M W P_{1 t+n}^{2}}\right)+\lambda_{2 t+n}^{*}\left(M W P_{2 t+n}^{1}-\widehat{M W P_{2 t+n}^{2}}\right)\right] \\
& -\sum_{n=0}^{\bar{n}} \frac{(1-\rho)^{n} \prod_{i=0}^{n} \sigma_{t+i}}{\prod_{i=1}^{n}\left(1+r_{t+i}\right)}\left[\tau_{x, t+n} \sum_{j}\left(\frac{\partial \tilde{x}_{1 t+n}^{j}}{\partial E_{t+n}}+\frac{\partial \tilde{x}_{2 t+n}^{j}}{\partial E_{t+n}}\right)+\tau_{y, t+n} \sum_{j}\left(\frac{\partial \tilde{y}_{1 t+n}^{j}}{\partial E_{t+n}}+\frac{\partial \tilde{y}_{2 t+n}^{j}}{\partial E_{t+n}}\right)\right] .
\end{aligned}
$$

Finally, if $\bar{n} \rightarrow \infty$, and by assuming that

$$
\lim _{\bar{n} \rightarrow \infty} \frac{(1-\rho)^{\bar{n}} \prod_{i=0}^{\bar{n}} \sigma_{t+i}}{\prod_{i=1}^{\bar{n}}\left(1+r_{t+i}\right)} \frac{\mu_{t+\bar{n}}}{\gamma_{t+\bar{n}}}=0
$$

we obtain equation (44) in the text.

To derive the commodity tax formulas in (45a) and (45b), first multiply (A.17) by $x_{1 t}^{1}$, lag (A.18) one period back and multiply by $x_{2 t}^{1}$. Then, multiply (A.20) by $x_{1 t}^{2}$ and lag (A.21) one period back and multiply by $x_{2 t}^{2}$. Adding the resulting expressions to (A.23) gives

$$
\tau_{x, t} \sum_{j}\left(\frac{\partial \tilde{x}_{1 t}^{j}}{\partial q_{x, t}}+\frac{\partial \tilde{x}_{2 t}^{j}}{\partial q_{x, t}}\right)+\tau_{y, t} \sum_{j}\left(\frac{\partial \tilde{y}_{1 t}^{j}}{\partial q_{x, t}}+\frac{\partial \tilde{y}_{2 t}^{j}}{\partial q_{x, t}}\right)=\lambda_{1 t}^{*}\left(x_{1 t}^{1}-\hat{x}_{1 t}^{2}\right)+\lambda_{2 t}^{*}\left(x_{2 t}^{1}-\hat{x}_{2 t}^{2}\right)+\frac{\mu_{t}}{\gamma_{t}} \sum_{j}\left(\frac{\partial \tilde{x}_{1 t}^{j}}{\partial q_{x, t}}+\frac{\partial \tilde{x}_{2 t}^{j}}{\partial q_{x, t}}\right) .
$$

Similarly, first multiply (A.17) by $y_{1 t}^{1}$, lag (A.18) one period back and multiply by $y_{2 t}^{1}$. Then, multiply (A.20) by $y_{1 t}^{2}$ and lag (A.21) one period back and multiply by $y_{2 t}^{2}$. Adding the resulting expressions to (A.24) produces 


$$
\tau_{x, t} \sum_{j}\left(\frac{\partial \tilde{x}_{1 t}^{j}}{\partial q_{y, t}}+\frac{\partial \tilde{x}_{2 t}^{j}}{\partial q_{y, t}}\right)+\tau_{y, t} \sum_{j}\left(\frac{\partial \tilde{y}_{1 t}^{j}}{\partial q_{y, t}}+\frac{\partial \tilde{y}_{2 t}^{j}}{\partial q_{y, t}}\right)=\lambda_{t}^{*}\left(y_{1 t}^{1}-\hat{y}_{1 t}^{2}\right)+\lambda_{2 t}^{*}\left(y_{2 t}^{1}-\hat{y}_{2 t}^{2}\right)+\frac{\mu_{t}}{\gamma_{t}} \sum_{j}\left(\frac{\partial \tilde{x}_{1 t}^{j}}{\partial q_{y, t}}+\frac{\partial \tilde{x}_{2 t}^{j}}{\partial q_{y, t}}\right) .
$$

Equations (A.34) and (A.35) imply the following equation system

$$
\left[\begin{array}{ll}
\sum_{j}\left(\frac{\partial \tilde{x}_{1 t}^{j}}{\partial q_{x, t}}+\frac{\partial \tilde{x}_{2 t}^{j}}{\partial q_{x, t}}\right) & \sum_{j}\left(\frac{\partial \tilde{y}_{1 t}^{j}}{\partial q_{x, t}}+\frac{\partial \tilde{y}_{2 t}^{j}}{\partial q_{x, t}}\right) \\
\sum_{j}\left(\frac{\partial \tilde{x}_{1 t}^{j}}{\partial q_{y, t}}+\frac{\partial \tilde{x}_{2 t}^{j}}{\partial q_{y, t}}\right) & \sum_{j}\left(\frac{\partial \tilde{y}_{1 t}^{j}}{\partial q_{y, t}}+\frac{\partial \tilde{y}_{2 t}^{j}}{\partial q_{y, t}}\right)
\end{array}\right] \cdot\left[\begin{array}{l}
\tau_{x, t} \\
\tau_{y, t}
\end{array}\right]=\left[\begin{array}{l}
\lambda_{1 t}^{*}\left(x_{1 t}^{1}-\hat{x}_{1 t}^{2}\right)+\lambda_{2 t}^{*}\left(x_{2 t}^{1}-\hat{x}_{2 t}^{2}\right)+\frac{\mu_{t}}{\gamma_{t}} \sum_{j}\left(\frac{\partial \tilde{x}_{1 t}^{j}}{\partial q_{x, t}}+\frac{\partial \tilde{x}_{2 t}^{j}}{\partial q_{x, t}}\right) \\
\lambda_{1 t}^{*}\left(y_{1 t}^{1}-\hat{y}_{1 t}^{2}\right)+\lambda_{2 t}^{*}\left(y_{2 t}^{1}-\hat{y}_{2 t}^{2}\right)+\frac{\mu_{t}}{\gamma_{t}} \sum_{j}\left(\frac{\partial \tilde{x}_{1 t}^{j}}{\partial q_{y, t}}+\frac{\partial \tilde{x}_{2 t}^{j}}{\partial q_{y, t}}\right)
\end{array}\right] .
$$

Using Cramer's rule to solve for $\tau_{x, t}$ and $\tau_{y, t}$ produces equations (45a) and (45b) in the text.

To derive the marginal capital income tax formula in equation (46a), let us first rewrite (A.17) and (A.18) to read

$$
\begin{aligned}
& \frac{\partial W}{\partial V_{t}} \frac{\partial v_{1 t}^{1}}{\partial b_{1 t}^{1}}=\lambda_{t} \frac{\partial \hat{v}_{1 t}^{2}}{\partial b_{1 t}^{1}}-\gamma_{t}\left(\tau_{x, t} \frac{\partial x_{1 t}^{1}}{\partial b_{1 t}^{1}}+\tau_{y, t} \frac{\partial y_{1 t}^{1}}{\partial b_{1 t}^{1}}-1\right)+\mu_{t} \frac{\partial x_{1 t}^{1}}{\partial b_{1 t}^{1}} \\
& \frac{\partial W}{\partial V_{t}} \beta \frac{\partial v_{2 t+1}^{1}}{\partial b_{2 t+1}^{1}}=\lambda_{t} \beta \frac{\partial \hat{v}_{2 t+1}^{2}}{\partial b_{2 t+1}^{1}}-\gamma_{t+1}\left(\tau_{x, t+1} \frac{\partial x_{2 t+1}^{1}}{\partial b_{2 t+1}^{1}}+\tau_{y, t+1} \frac{\partial y_{2 t+1}^{1}}{\partial b_{2 t+1}^{1}}-1\right)+\mu_{t+1} \frac{\partial x_{2 t+1}^{1}}{\partial b_{2 t+1}^{1}}
\end{aligned}
$$

Divide (A.37) by (A.38) and use $M R S_{b_{1}, b_{2}}^{1, t}=\frac{\partial v_{1 t}^{1} / \partial b_{1 t}^{1}}{\beta \partial v_{2 t+1}^{1} / \partial b_{2 t+1}^{1}}$. We obtain

$$
M R S_{b_{1}, b_{2}}^{1, t}=\frac{\lambda_{t} \frac{\partial \hat{v}_{1 t}^{2}}{\partial b_{1 t}^{1}}+\gamma_{t}\left(1-\tau_{x, t} \frac{\partial x_{1 t}^{1}}{\partial b_{1 t}^{1}}-\tau_{y, t} \frac{\partial y_{1 t}^{1}}{\partial b_{1 t}^{1}}\right)+\mu_{t} \frac{\partial x_{1 t}^{1}}{\partial b_{1 t}^{1}}}{\lambda_{t} \beta \frac{\partial \hat{v}_{2 t+1}^{2}}{\partial b_{2 t+1}^{1}}+\gamma_{t+1}\left(1-\tau_{x, t+1} \frac{\partial x_{2 t+1}^{1}}{\partial b_{2 t+1}^{1}}-\tau_{y, t+1} \frac{\partial y_{2 t+1}^{1}}{\partial b_{2 t+1}^{1}}\right)+\mu_{t+1} \frac{\partial x_{2 t+1}^{1}}{\partial b_{2 t+1}^{1}}}
$$

Multiply up the denominator on the right hand side and rearrange

$$
\begin{aligned}
& \gamma_{t}-\gamma_{t+1} M R S_{b_{1}, b_{2}}^{1, t}=\lambda_{t} \beta \frac{\partial \hat{v}_{2 t+1}^{2}}{\partial b_{2 t+1}^{1}} M R S_{b_{1}, b_{2}}^{1, t}-\lambda_{t} \frac{\partial \hat{v}_{1 t}^{2}}{\partial b_{1 t}^{1}} \\
& \gamma_{t}\left(\tau_{x, t}-\frac{\mu_{t}}{\gamma_{t}}\right) \frac{\partial x_{1 t}^{1}}{\partial b_{1 t}^{1}}+\gamma_{t} \tau_{y, t} \frac{\partial y_{1 t}^{1}}{\partial b_{1 t}^{1}}-M R S_{b_{1}, b_{2}}^{1, t}\left[\gamma_{t+1}\left(\tau_{x, t+1}+\frac{\mu_{t+1}}{\gamma_{t+1}}\right) \frac{\partial x_{2 t+1}^{1}}{\partial b_{2 t+1}^{1}}+\gamma_{t+1} \tau_{y, t+1} \frac{\partial y_{2 t+1}^{1}}{\partial b_{2 t+1}^{1}}\right]
\end{aligned}
$$

Divide by $\gamma_{t}$, use $\gamma_{t}=\gamma_{t+1}\left(1+r_{t+1}\right)$, and rearrange

$$
\begin{aligned}
\frac{1}{1+r_{t+1}}\left[\left(1+r_{t+1}\right)-M R S_{b_{1}, b_{2}}^{1, t}\right] & =\frac{\lambda_{t}}{\gamma_{t}} \beta \frac{\partial \hat{v}_{2 t+1}^{2}}{\partial b_{2 t+1}^{1}}\left(M R S_{b_{1}, b_{2}}^{1, t}-\widehat{M R S}_{b_{1}, b_{2}}^{2, t}\right)+\left[\left(\tau_{x, t}-\frac{\mu_{t}}{\gamma_{t}}\right) \frac{\partial x_{1 t}^{1}}{\partial b_{1 t}^{1}}+\tau_{y, t} \frac{\partial y_{1 t}^{1}}{\partial b_{1 t}^{1}}\right] \\
& -\frac{M R S_{b_{1}, b_{2}}^{1, t}}{\left(1+r_{t+1}\right)}\left[\left(\tau_{x, t+1}-\frac{\mu_{t+1}}{\gamma_{t+1}}\right) \frac{\partial x_{2 t+1}^{1}}{\partial b_{2 t+1}^{1}}+\tau_{y, t+1} \frac{\partial y_{2 t+1}^{1}}{\partial b_{2 t+1}^{1}}\right] .
\end{aligned}
$$

By using the private first-order condition for saving in (38) and solving for $d \Phi_{1 t+1}^{1} / d I_{1 t+1}^{1}$, we obtain equation (46a) in the text. Equation (46b) is derived analogously.

\section{References}

Andersen, P. (1983) On Rent of Fishing Grounds: a Translation of Jens Warming's 1911 article, with an introduction", History of Political Economy 5, 391-96. 
Aronsson, T. and S. Blomquist (2003) Optimal Taxation, Global Externalities and Labor Mobility. Journal of Public Economics 87, 2749-2764.

Aronsson, T., P-O. Johansson, and K-G. Löfgren (1997) Welfare Measurement, Sustainability and Green National Accounting: A Growth Theoretical Approach. Cheltenham: Edward Elgar Publishing Limited.

Aronsson, T. and O. Johansson-Stenman (2008) When the Joneses' Consumption Hurts: Optimal Public Good Provision and Nonlinear Income Taxation. Journal of Public Economics 92, 986-997.

Aronsson, T. and O. Johansson-Stenman (2010) Positional Concerns in an OLG Model: Optimal Labor and Capital Income Taxation. International Economic Review 51, 1071-1095.

Aronsson, T. and O. Johansson-Stenman (2015) Keeping up with the Joneses, the Smiths and the Tanakas: On International Tax Coordination and Social Comparisons. Journal of Public Economics 131, 71-86.

Aronsson, T. and A. Mannberg (2014) Relative Consumption of Housing: Marginal Saving Subsidies and Income Taxes as a Second-Best Policy? Journal of Economic Behavior and Organization 116, 439-450.

Aronsson, T., T. Jonsson, and T. Sjögren (2006) Environmental Policy and Optimal Taxation in a Decentralized Economic Federation. FinanzArchiv 62, 437-454.

Aronsson, T., L. Persson, and T. Sjögren (2014) Mixed Taxation and Transboundary Externalities: A Model with Large Jurisdictions. Public Finance Review 42, 254-282.

Aronsson, T. and T. Sjögren (2010) An Optimal-Tax Approach to Alcohol Policy. FinanzArchiv 66, 153-169.

Aronsson, T. and T. Sjögren (2016) Quasi-Hyperbolic Discounting, Paternalism and Optimal Mixed Taxation. Mathematical Social Sciences 84, 24-36.

Atkinson, A. B. and N. Stern (1974) Pigou, Taxation and Public Goods. Review of Economic Studies 41, 119-128.

Bovenberg, L. and L. Goulder (1997) Costs of Environmentally Motivated Taxes in the Presence of Other Taxes: General Equilibrium Analyses. National Tax Journal 50, 59-88.

Bovenberg, L. and R. de Mooij (1994) Environmental Levies and Distortionary Taxation. American Economic Review 84, 1085-1089. 
Brett, C. (1997) A Note on Nonlinear Taxation in an Overlapping Generations Model. Mimeo, Depatment of Economics, University of Essex.

Brett, C. and J. Weymark (2008) Optimal Nonlinear Taxation of Income and Savings Without Commitment. Working paper 09-W05, Department of Economics, Vanderbilt University.

Brock, W.A. (1977) A Polluted Golden Age. In V.L. Smith (ed.), Economics of Natural and Environmental Resources, New York: Gorden \& Breach.

Christiansen, V. (1984) Which Commodity Taxes Should Supplement the Income Tax? Journal of Public Economics 24, 195-220.

Conconi, P. (2003), Green Lobbies and Transboundary Pollution in Lage Open Economies. Journal of Environmental Economics and Management 59, 399-422.

Cremer, H. and F. Gahvari (2001) Second-Best Taxation of Emissions and Pollution Goods. Journal of Public Economics 80, 169-197.

Cremer, H. and F. Gahvari (2005) Environmental Taxation in Open Economies: Unilateralism or Partial Harmonization. Southern Economic Journal 72, 352-371.

Cremer, H., F. Gahvari, and N. Ladoux (1998) Externalities and Optimal Taxation. Journal of Public Economics 70, 343-364.

Diamond, P. (1973) Consumption Externalities and Imperfect Corrective Pricing. Bell Journal of Economics and Management Science 4, 526-538.

Eckerstorfer, P. and R. Wendner (2013) Asymmetric and Non-Atmospheric Consumption Externalities, and Efficient Consumption Taxation. Journal of Public Economics 106, 4256.

Edwards, J., M. Keen, and M. Tuomala (1994) Income Tax, Commodity Tax and Public Good Provision: A Brief Gudie. FinansArchiv 51, 472-487.

Gurzgen, N., and M. Rauscher. (2000) Environmental Policy, Intra-industry Trade and Transfrontier Pollution. Environmental and Resource Economics 17, 59-71.

Guo, J-T. and A. Krause (2015) Dynamic Nonlinear Income Taxation with Quasi-Hyperbolic Discounting and no Commitment. Journal of Economic Behavior \& Organization 109, 101--119.

Keeler, E., M. Spence, and R. Zeckhauser, (1971) The Optimal Control of Pollution. Journal of Economic Theory 4, 19-34. 
Lai, Y.-B., and C.-H. Hu. (2005) Trade Liberalization and Transboundary Pollution. Environmental Economics and Policy Studies 7, 1-14.

Montgomery, D. (1972) Markets in Licenses and Efficient Pollution Control Programs. Journal of Economic Theory 5. 395-418.

Naito, H. (1999) Re-examination of Uniform Commodity Taxes under a Non-linear Income Tax System and its Implication for Production Efficiency. Journal of Public Economics 71,165188.

Oswald, A. (1983) Altruism, Jealousy and the Theory of Optimal Non-Linear Taxation. Journal of Public Economics 20, 77-87.

Ordover, J. E. and E. S. Phelps, (1979) The Concept of Optimal Taxation in the Overlapping Generations Model of Capital and Wealth. Journal of Public Economics 12, 1-26.

Pigou, A. C. (1920) The Economics of Welfare. London: Macmillan

Pirttilä, J. and M. Tuomala (1997) Income Tax, Commodity Tax and Environmental Policy. International Tax and Public Finance 4, 379-393.

Pirttilä, J. and M. Tuomala (2001) On Optimal Non-Linear Taxation and Public Good Provision in an Overlapping Generations Economy. Journal of Public Economics 79, 485-501.

Sandmo, A. (1975) Optimal Taxation in the Presence of Externalities. Swedish Journal of Economics 77, 86-98.

Sandmo, A. (1976) Direct Versus Indirect Pigouvian Taxation. European Economic Review 7, 337-349.

Sandmo, A. (1980) Anomaly and Stability in the Theory of Externalities. Quarterly Journal of Economics 94, 799-807.

Stern, N.H. (1982) Optimum Taxation with Errors in Administration. Journal of Public Economics 17, 181-211.

Stiglitz, J. E. (1982) Self-Selection and Pareto Efficient Taxation. Journal of Public Economics 17, 213-240.

Tahvonen, O. and J. Kuuluvainen (1993) Economic Growth, Pollution, and Renewable Resources. Journal of Environmental Economics and Management 24, 101-118.

Tuomala, M. (1990) Optimal Income Tax and Redistribution. Oxford: Clarendon Press.

Warming, J. (1911) Om Grundrente af Fiskegrunde. Nationalökonomisk Tidskrift 49, 499-505. 